\title{
Internet Addictions Outside of Europe: A Systematic Literature Review
}

\author{
Daria J. Kuss ${ }^{1 *}$
}

Anne Marie Kristensen ${ }^{1,2}$

Olatz Lopez-Fernandez ${ }^{3}$

${ }^{1}$ International Gaming Research Unit, Cyberpsychology Research Group, Psychology Department, Nottingham Trent University, Nottingham, United Kingdom

${ }^{2}$ Center for Visual Cognition, Department of Psychology, University of Copenhagen, Denmark

${ }^{3}$ Monash Addiction Research Centre, Turning Point, Easter Health Clinical School, Monash University, Melbourne, Australia

*Corresponding author. Email: daria.kuss@ntu.ac.uk; tel.: +44 1158484153

Funding: This research was supported by the European Parliament through the Scientific Foresight Unit (STOA), Directorate for impact assessment and European added value, grant number SQM 02 Y066 (EPRS/STOA/SER/17/226N; ED number 03210-01-00/5218/107321).

Acknowledgments: We would like to acknowledge the contribution of the European Parliament through the Science and Technology Options Assessment (STOA) Panel, including Gianluca Quaglio, Damir Plese, and Emilia Bandeira Morais, and that of Nottingham Trent University for facilitating the development of the project, which included a research assistant for data collection: Bailey Foster. 
Conflicts of Interest: The authors declare no conflict of interest.

Page 2 of 49 


\begin{abstract}
Background and aims: The growing problem of Internet addiction has been acknowledged through the inclusion of Internet Gaming Disorder (IGD) in the American Psychiatric Association's fifth Diagnostic and Statistical Manual of Mental Disorders in April 2013. In response to a recent review report on the research published in Europe since the adoption, this review summarizes and investigates studies published outside of Europe between April 2013 and
\end{abstract} September 2019.

Methods: Literature on internet addiction was included and reviewed critically following the Preferred Reporting Items for Systematic Reviews and MetaAnalyses (PRISMA) guidelines, with the objectives to (i) highlight the main findings in explorative and intervention studies and (ii) to investigate the cultural similarities and differences within the extra-European. A critical look is cast on the validity and reliability of the studies in question.

Results: A total of 64 studies met the inclusion criteria. The majority of studies investigated internet addiction and IGD; however, studies on addiction to online gambling, online pornography, and social media addiction were also included. Demographically East Asia was highly represented through studies from China, Japan, and South Korea. Prevalence rates of generalised internet addiction varied from $12.6 \%$ to $67.5 \%$. The main findings revealed a range of risk factors associated with online addictions, such as psychological distress, mood disorders, suicidality, impulsivity, aggression, and sleep problems. Most of the intervention studies made use of a cognitive behavioural therapy approach, although other interventions appeared effective in reducing addiction symptoms. Further katamnestic research is needed to follow-up on intervention studies.

Conclusions: Based on the consistent findings of positive associations between online addictions and mental health problems across cultures in combination with relatively high prevalence rates amongst adolescents and university students, further research is needed and prevention strategies and treatment offers require developing and implementing.

Keywords: Internet addiction; problematic Internet use; systematic literature review; PRISMA; international; gaming disorder 
Page 4 of 49 


\section{Introduction}

Individuals who use the Internet in an excessive way do not become addicted to the medium of the Internet, but to the behaviours they engage in online (Meerkerk et al., 2009). Accordingly, the Internet can be considered a tool used to access online content and specific applications (Kuss et al., 2013). Some researchers are sceptical about the feasibility of IA as a construct and favour the examination of specific online activities instead (e.g., Starcevic \& Aboujaoude, 2016). Generalised internet addiction (GIA) is a broad term which may cover, and does not differentiate between, a range of specific online addictions such as gaming disorder, pornography addiction, online gambling addiction and social media addiction. According to the biopsychosocial model of addictions, it incorporates symptoms of behavioural addictions, specifically, salience, mood modification, tolerance, withdrawal, conflict and relapse (Griffiths, 2005). The acknowledgement and empirical understanding of these disorders as behavioural addictions, affecting lives of individuals, has significantly increased within the last twenty years. Prevalence estimates for GIA in large epidemiological studies range between $1 \%$ of the general population in Germany (Rumpf et al., 2014) to $18.7 \%$ of Taiwanese adolescents (Lin et al., 2014), indicating there may be cross-cultural differences in presentation and assessment. GIA causes severe problems in everyday life, and comorbid psychiatric symptoms are commonly found (Kuss \& Lopez-Fernandez, 2016; Robbins \& Clark, 2015). GIA and its various sub-forms have been associated with symptoms of substance-related disorders, depression, anxiety, bipolar and personality disorders, with co-occurring disorders representing a more complex clinical picture (Park et al., 2017; Wölfling et al., 2015).

It has been noted that the problem can only be understood when contextual variables are taken into consideration, including the sociocultural and digital environment in which the problematic behaviours have evolved and take place (Kuss, 2013; Lopez-Fernandez, 2018). Research indicates that there exist cross-cultural differences in GIA regarding instruments, prevalence, symptom experience, prevention, and treatment initiatives (King et al., 2018; King et al., 2017; Lopez-Fernandez, 2015). The early recognition and adoption of diagnostic and preventative frameworks in some countries supports the contention that a comprehensive approach including a sociocultural perspective is required for an in-depth understanding of GIA and its sub-forms, including the internationally recognised Gaming Disorder, which has now been included in the World Health Organisation's (WHO) most recent eleventh edition of the International Classification of Diseases (ICD-11; 2019) as behavioural addiction. Accordingly, Gaming Disorder is understood as a pattern of gaming where the individual loses control over their behaviours, gives increasing priority to gaming in favour of other activities, 
and continues with the behaviours despite experiencing various negative consequences. In line with this, GIA has received scientific recognition across the world and especially South East Asia. In South Korea and China, GIA and online gaming addiction are considered national health threats (Starcevic, 2013). Correspondingly, from an international perspective, South Korea is paving the way regarding prevention initiatives as the government has been very forthcoming with initiatives and strategies that address prevention requirements comprehensively. By contrast, in Western countries, the diagnostic and clinical recognition of Gaming Disorder has seen a slower pace, leading to less developed and focused prevention approaches mostly developed by Non-Governmental Organisations (NGOs) and private organisations (King et al., 2018).

In 2019, for the first time, European studies on GIA were reviewed (Lopez-Fernandez \& Kuss, 2019; Lopez-Fernandez \& Kuss, 2020) since the inclusion of Internet Gaming Disorder (IGD) in Appendix 3 of the fifth edition of the American Psychiatric Association's (APA) Diagnostic and Statistical Manual for Mental Disorders (DSM-5) in 2013. Based on the available literature, studies were classified into those assessing usages of the Internet, including generalised IA, and particular usages, namely online gaming, and gambling addiction in Europe. Regarding samples, most participants were educated adolescents and young males, often with co-occurring mental health problems. Cognitive behavioural therapy (CBT) was indicated as treatment approach showing significant promise to alleviate symptoms. Correspondingly, the aim of the present systematic literature review is to examine the studies published outside of Europe following the inclusion of IGD in the DSM-5. The objectives are to (i) highlight the main findings in explorative and intervention studies, and (ii) to investigate the cultural similarities and differences within the extra-European regions. A critical look is cast on the validity and reliability of the studies in question.

\section{Methodology}

A comprehensive literature review was conducted using the databases Web of Science and PsycINFO between February 2018 and September 2019 at Nottingham Trent University. The following search string was used: ("Internet” OR “online” OR "game*” OR "gaming" OR "video gam*" OR "videogame*" OR "video-game*" OR "social network*" OR "social media") AND ("Addict*" OR "compuls*" OR "problem*" OR "disorder" OR "pathology*" OR "excess*") AND ("clinic*" OR "treat*" OR "therap*" OR "harm*" OR "risk factor" OR "prevent*"). The studies included were restricted to peer-reviewed journal articles. Articles 
published from April 2013 onwards were included given IGD was included in the DSM-5 manual at that time (APA, 2013).

After duplicates were removed, studies were selected in accordance with the following inclusion criteria: (1) contain quantitative, qualitative, and mixed methods approaches (empirical data); (2) assess generalised Internet, gaming, gambling, or other online addictions (e.g., social networking) outside of Europe, as the equivalent European studies are covered in the recent European report (Lopez-Fernandez \& Kuss, 2019, 2020); (3) be published from April 2013 when the IGD diagnosis was first introduced into the APA's most recent classification system, the DSM-5; (4) include community samples, clinical samples, and/or clinical interventions; (5) provide a full-text article; (6) be published in English, German, Spanish, Italian, Portuguese, Danish or French, as the present authors speak these languages. Studies were excluded based on the following exclusion criteria: (i) theoretical research papers (e.g., reviews, meta-analyses); (ii) assessing other behavioural addictions which do not involve Internet use (e.g., offline gambling) or substance-related addictions (e.g., alcoholism); (iii) published before April 2013; (iv) deriving from sources other than peer-reviewed journals (e.g., non-peer-reviewed journals, conference abstracts, chapters, books, errata/corrections, editorials, and dissertations); (v) published in other languages the present authors do not speak. Following a thorough inspection of the articles' titles and abstracts, the articles that did not meet the inclusion criteria were excluded. 


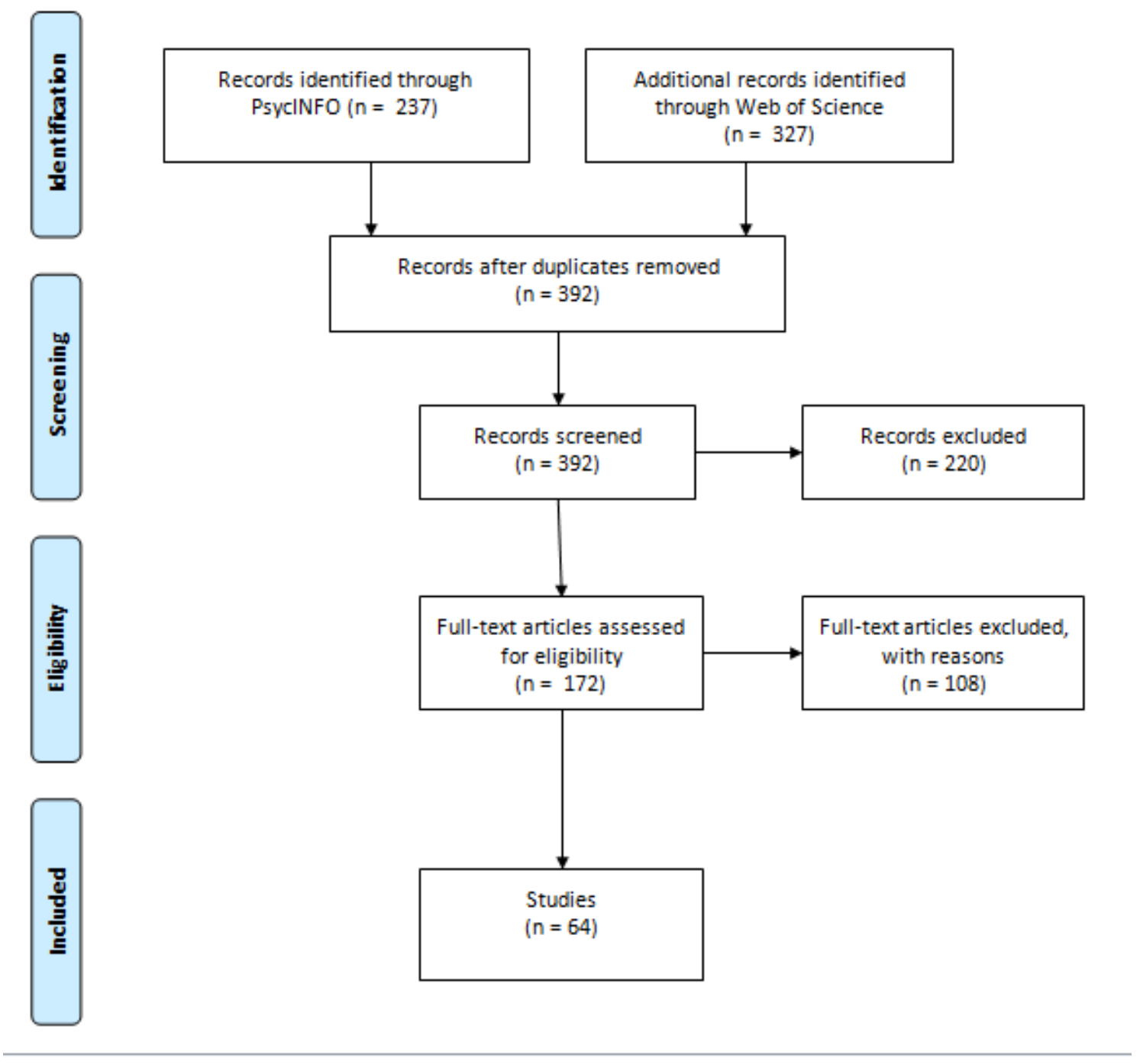

Figure 1 - PRISMA Diagram of study selection processes.

Figure 1 shows the study selection process following the Preferred Reporting Items for Systematic Reviews and Meta-Analyses (PRISMA) guidelines (Shamseer et al., 2015). The search resulted in 64 studies which were included in the current review after sifting through duplicates and articles meeting aforementioned inclusion criteria, but not exclusion criteria. Data were organised into five main topics of generalised Internet addiction (GIA), IGD, Internet gambling addiction, Internet pornography addiction and addiction to social media. These clusters were then subdivided into studies on risk factors and intervention studies.

\section{Results and Discussion}

The map below (Figure 2) showed the included studies were primarily conducted in Asia and North America. The database search identified 64 articles, which have been divided based on addictions to specific Internet behaviours, i.e., generalised Internet addiction, GIA ( $n=32)$, and 
specific Internet behaviours $(n=32)$, ordered from higher to lower frequency: IGD $(n=25)$, Internet gambling addiction $(n=4)$, Internet pornography addiction $(n=2)$ and social media addiction $(n=1)$. These five constructs are treated separately because research suggests their prevalence rates and the clinical samples appear different from each other. Whilst the clinical samples in the studies on GIA are generally spread evenly across the genders, IGD appeared to affect mainly adolescent males and addiction to online gambling and pornography appeared to be an issue mainly in the adult population. In the review, clinical and community samples are treated together because in community samples, the focus is typically on the characteristics of clinical and sub-clinical subjects. Prevention studies included are often shaped similarly to school-based clinical interventions. Furthermore, samples of children, adolescents, and adults are addressed together because the types of problems associated with these addictions do not appear to differ between age groups.

Figure 2: Distribution of Studies by World Region (excluding Europe)

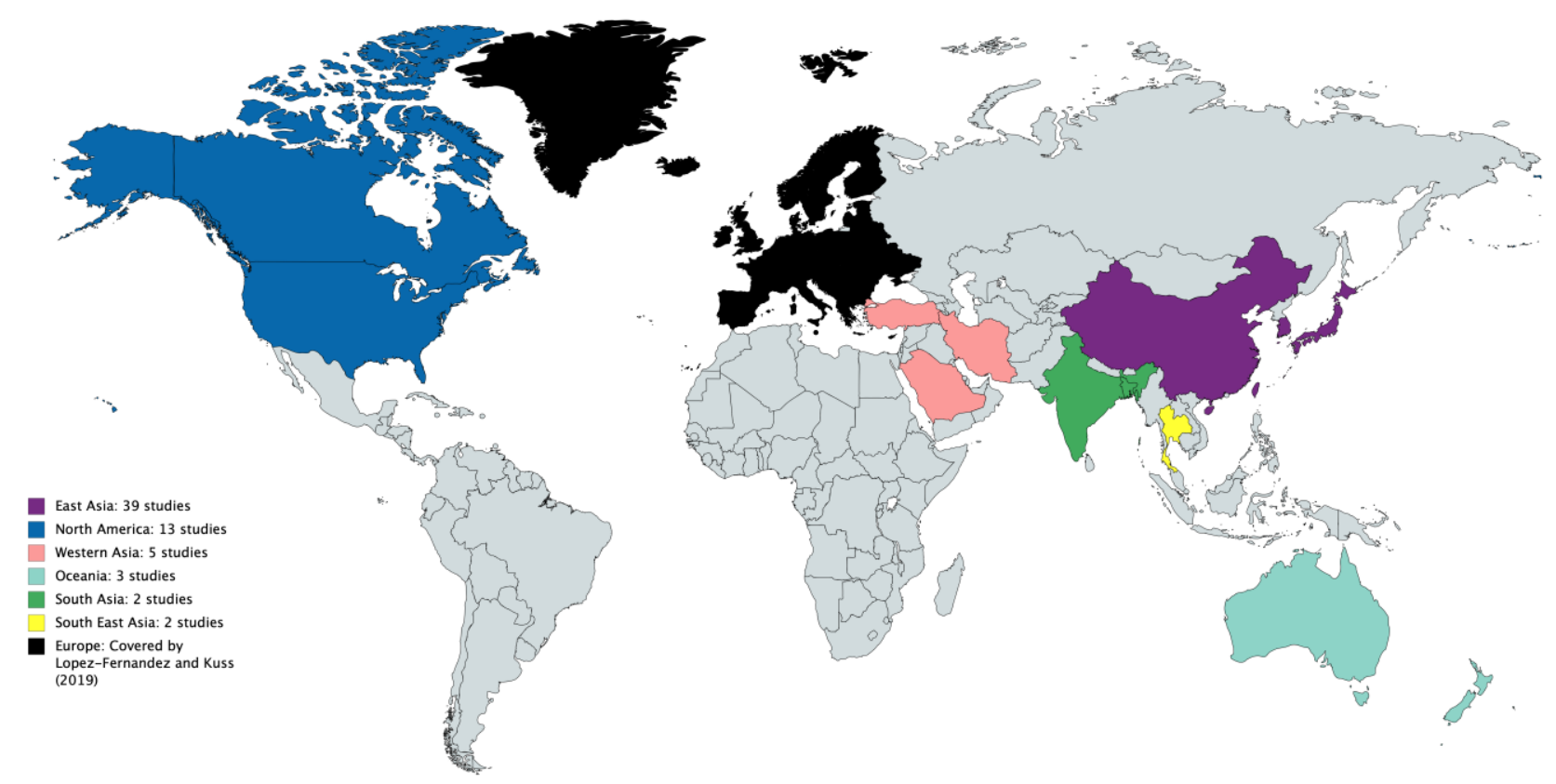

\subsection{Generalised Internet Addiction}

A total of 32 studies which have assessed IA can be subdivided into those focusing on risk factors $(n=21)$ and interventions $(n=11)$ for generalised Internet addiction.

\subsubsection{Risk Factors: Samples and Prevalence Rates}

A total of 21 studies addressed risk. Sample sizes varied from 22 adults (Wang \& GriskovaBulanova, 2018) to 3.224 students (ElSalhy et al., 2019). Prevalence rates ranged from $14.7 \%$ in a Taiwanese sample (Shang-Yu Yang et al., 2019) to $67.5 \%$ in a Saudi Arabian sample 
(Hasan \& Jaber, 2019). Six studies were from Japan (ElSalhy et al., 2019; Kawabe et al., 2019; Seki et al., 2019; So et al., 2017, 2019; Tateno et al., 2019) and four were from Taiwan (P.-H. Lin et al., 2019, 2019; H.-C. Liu et al., 2017; Pan \& Yeh, 2018). The majority of the participants in the studies assessing risk factors were adolescents, and slightly more than half of the samples were male. Unless otherwise stated, all studies used cross-sectional surveys, which were filled out by hand or online. Nine of the 13 studies which reported prevalence rates (ElSalhy et al., 2019; Hasan \& Jaber, 2019; Kawabe et al., 2019; Lim et al., 2015; P.-H. Lin et al., 2019; Mamun et al., 2019; Seki et al., 2019; Tateno et al., 2019; Shang-Yu Yang et al., 2019) used Young's Internet Addiction Test (IAT) (Young, 1998a), J. Tang et al. (2014) used a Chinese 10-item version of the IAT (Shek et al., 2008), two studies (H.-C. Liu et al., 2017; Pan \& Yeh, 2018) made use of the Chen Internet Addiction Scale (CIAS) (S.-H. Chen et al., 2003), and one study (Chamberlain et al., 2017) used Young's Diagnostic Questionnaire (YDQ) (Young, 1998b).

The following 13 studies present prevalence rates. In J. Tang et al.'s study (2014), 12.6\% of a sample of 1.076 Chinese adolescents ( $54.1 \%$ males) met the IA criteria ( $\geq 5$ out of 10 items) measured by a cross-sectional survey and a psychiatric interview. $14.7 \%$ of the sample of 503 Taiwanese female junior college students scored above 50 on the IAT (P.-H. Lin et al., 2019; Shang-Yu Yang et al., 2019). H.-C. Liu et al. (2017) recruited 2.749 senior high school students (64.2\% females) from Taiwan, and the prevalence of IA was $17.1 \%$ (CIAS $\geq 64)$. In Chamberlain et al.'s study (2017), 18.0\% of their clinical sample of 206 adult American gamblers had problematic Internet use (PIU) (YDQ $\geq 5$ ). The prevalence rate was $23.0 \%$ in 1.507 Taiwanese adolescents (82.3\% males), with a CIAS score above 63 (Pan \& Yeh, 2018). In a sample of 853 Japanese adolescents (54.4\% females), $23.7 \%$ appeared to be affected by GIA (IAT $\geq 40$ ) (Kawabe et al., 2019). In a community sample of 714 South Korean adolescents (54.5 males), 28.6\% were found to have an IAT score $\geq 40$ (Lim et al., 2015). Mamun et al. (2019) found the rate of PIU to be $32.6 \%$ in a sample of 405 university students (50.1\% males) in Bangladesh (IAT $\geq 40$ ). In a sample of 478 Japanese college and university students (73\% females), $47.7 \%$ had an IAT $\geq 40$ (Tateno et al., 2019). The prevalence in 3.224 Japanese students (61.6\% females) aged 9-25 was $25.6 \%, 37.3 \%, 52.7 \%$, and $60 \%$ among students in elementary, junior high and senior high schools, and universities (IAT $\geq 40$ ) (ElSalhy et al., 2019). In 3.251 Japanese university students (52.4\% females) GIA was 48.5\% (IAT $\geq 40$ ) (Seki et al., 2019), and odds ratios were higher for the humanities and fine arts departments compared to science, pharmaceutical sciences and medicine. GIA was found to be 
present in $67.5 \%$ of a sample counting 163 female South Arabian nursing students (IAT $\geq 50$ ) (Hasan \& Jaber, 2019).

As the cut-off scores across studies were defined differently, it is difficult to compare the prevalence rates, but prevalence rates of possible addiction based on scoring $\geq 50$ on the IAT range from 14.7\% (Shang-Yu Yang et al., 2019) to 67.5\% (Hasan \& Jaber, 2019). Here, both samples consist of females only and are not representative of the respective population groups. However, the samples shared similarities, consisting of female college students from a Chinese technical college in their late teens and Saudi Arabian nursing students in their early twenties. The samples' main dissimilarity might lie in the transition from being a college student, working intensely to do well and be admitted to university, being a university student, who plans and structures time and course work more independently. In this case, a qualitative aspect to the research could aid discovering why prevalence rates might be relatively high or low. Cultural differences between Saudi Arabia and China might also influence the prevalence rates; according to L. Chen and Nath (2016), Chinese participants have very low indulgence scores, indicating strong control over impulses and desires, which might explain the low prevalence in the Chinese sample. All samples mentioned above, apart from the clinical gambling sample in Chamberlain et al.'s study (2017), assessed GIA in samples of children, adolescents, and young adults mainly taking place in East Asian countries. None of these prevalence rates represent the general adult population; however, the studies that involved samples of school and university students from several institutions and areas (ElSalhy et al., 2019; H.-C. Liu et al., 2017; Tateno et al., 2019) are more likely to be representative of national student populations.

Apart from the studies including prevalence rates presented above, the samples used in this section on risk factors in GIA included a clinical sample of 205 psychiatrically hospitalized American adolescents (62.0\% female), in which $72.7 \%$ endorsed at least one out of three GIA items, and 23\% endorsed all three (Gansner et al., 2019). Wang and Griskova-Bulanova (2018) involved a non-clinical sample of 22 adults (54.5\% males). Senormanci et al. (2014) conducted a study on a clinical sample of 40 young adult Turkish males, and the study by Hou et al. (2019) recruited 32 Internet addicted and 32 non-addicted adult Chinese males. The South Korean adolescent clinical sample recruited by Ryu et al. (2019) consisted of 103 children and adolescents (aged 7-18) with excessive Internet use (70.9\% males) and their caregivers (92.4\% females). Gao et al. (2019) worked with a community sample of 2.271 Chinese adolescents (54.3\% females). So et al. (2017) reported the prevalence of GIA among their 83 adolescent participants with Autism Spectrum Disorder (ASD) alone to be $10.8 \%$ (65.1\% males), in the 24 participants with attention deficit hyperactivity disorder (ADHD) alone it was $12.5 \%$ 
(58.3\% males), and in the 25 participants with comorbid ASD and ADHD it was 20\% (60\% males). When So et al. (2019) returned to their sample after two years, $67.4 \%$ of their participants remained, and the overall Internet addiction prevalence had dropped from $12.9 \%$ to $11.2 \%$.

\subsubsection{Risk Factors Associated with GIA}

The most prominent risk factors for GIA are depression and psychological distress (ElSalhy et al., 2019; Gao et al., 2019; Hasan \& Jaber, 2019; Lim et al., 2015; Mamun et al., 2019; Seki et al., 2019; J. Tang et al., 2014; Tateno et al., 2019; Wang \& Griskova-Bulanova, 2018; Shang-Yu Yang et al., 2019), self-harm and suicidality (Gansner et al., 2019; H.-C. Liu et al., 2017; Pan \& Yeh, 2018), aggression and suppressed anger (Chamberlain et al., 2017; Gansner et al., 2019; Lim et al., 2015; Senormanci et al., 2014), sleep problems and duration (ElSalhy et al., 2019; Kawabe et al., 2019; P.-H. Lin et al., 2019), impulsivity (Lim et al., 2015; So et al., 2017, 2019; J. Tang et al., 2014), and comorbid Autism Spectrum Disorder and ADHD (So et al., 2017, 2019). Twelve of the GIA studies found depression and psychological distress as risk factors (ElSalhy et al., 2019; Gao et al., 2019; Hasan \& Jaber, 2019; Lim et al., 2015; Mamun et al., 2019; Ryu et al., 2019; Seki et al., 2019; Senormanci et al., 2014; J. Tang et al., 2014; Tateno et al., 2019; Wang \& Griskova-Bulanova, 2018; Shang-Yu Yang et al., 2019). In these studies, GIA symptoms were found to be associated with e-messaging, social networking services, holiday Internet usage and psychological distress (ElSalhy et al., 2019). Significant associations with stress, coping behaviours and depression were identified (Hasan \& Jaber, 2019), alongside stress being associated with reduced school interest and maladaptive cognitions, leading to GIA (Gao et al., 2019).

Depression was a prominent risk factor amongst the studies in this review. A total of $67.7 \%$ of the IA adolescents in a community sample reported emotional symptoms, including depression, anxiety, obsession, impulsive behaviour, and the main GIA risk factors were being male, younger, having a poor relationship with parents, and self-reported depression (J. Tang et al., 2014). Individuals with PIU had significantly higher mean scores on depression, anxiety and stress subscales (Mamun et al., 2019), and similarly, IAT scores were positively associated with depression scores (Wang \& Griskova-Bulanova, 2018). Significant correlations were found between health-related behaviours, depression and GIA (Shang-Yu Yang et al., 2019), and the odds ratio (OR) for depression increased with severity of GIA from 2.87, when suffering from mild addiction, to 7.31 in cases of severe addiction (Seki et al., 2019). Similarly, Ryu et al. (2019) found groups at moderate risk of and suffering from GIA showed significantly 
higher levels of Internet and smartphone addiction, anxiety, depression, impulsivity, aggression, stress, and lower self-esteem compared with the mild risk group. Depression, anxiety and impulsivity had partial to full mediating effects on the ability to aggression to predict GIA, but no effect on the ability of GIA to predict aggression (Lim et al., 2015). In an exploration of Event-Related Potential (ERP) patterns, when subjects were presented photos of intimacy, conflict, happiness and loneliness, researchers found social cognitive function and attention function was impaired in the IA group (Hou et al., 2019). Tateno et al. (2019) found subjects at high risk for hikikomori, severe social withdrawal, had longer Internet usage time and higher scores on IAT.

In a sample of psychiatrically hospitalized American adolescents, Gansner et al. (2019) found having a developmental or aggressive disorder and suicidality, but not a depressive disorder significantly increased the PIU risk. Psychiatric comorbidities were not measured as admission was based on a primary disorder rather than considering possible co-occurring psychiatric problems. Given that suicidality significantly increased PIU in this sample and suicidality is a strong marker for severe depressive disorder, it is possible that those individuals with higher PIU scores also experienced some depressive symptoms. Based on these findings, with the exception of the studies by Gansner et al. (2019), depression and psychological distress were consistently associated with GIA (Hasan \& Jaber, 2019; Mamun et al., 2019; J. Tang et al., 2014), symptoms increasing with GIA severity (Seki et al., 2019; Wang \& GriskovaBulanova, 2018; Shang-Yu Yang et al., 2019).

Three studies addressed GIA, Internet exposure to suicidal content, and self-harm (Gansner et al., 2019; H.-C. Liu et al., 2017; Pan \& Yeh, 2018). In a sample of Taiwanese senior high school students, $9.1 \%$ reported self-harm behaviour, and the prevalence of GIA was $30.8 \%$ in the self-harm group, compared to $15.6 \%$ in the rest of the sample (H.-C. Liu et al., 2017). GIA and Internet exposure to suicidal thoughts were both significantly related to an increased risk of self-harm. In a sample of Taiwanese adolescents, the relative risk of developing self-harm behaviour was 2.41 if diagnosed with GIA, when controlling for confounding factors such as sex, poor sleep quality, depressive symptoms, and psychological health (Pan \& Yeh, 2018), and in a sample of 205 psychiatrically hospitalized American adolescents (62.0\% female), PIU severity was significantly associated with being female, sexting, cyberbullying, and increased suicidality within the last year (Gansner et al., 2019).

Extra attention should be paid to young people experiencing symptoms of stress (Hasan \& Jaber, 2019; Mamun et al., 2019), depression (Hasan \& Jaber, 2019; Mamun et al., 2019; Ryu et al., 2019; Seki et al., 2019; J. Tang et al., 2014; Wang \& Griskova-Bulanova, 2018; Shang- 
Yu Yang et al., 2019), psychological distress (ElSalhy et al., 2019), social withdrawal (Tateno et al., 2019), coping behaviours (Hasan \& Jaber, 2019), maladaptive cognitions and loss of school interest (Gao et al., 2019), anxiety (Mamun et al., 2019; Ryu et al., 2019; J. Tang et al., 2014), obsession and compulsive behaviour (J. Tang et al., 2014), weakened decision making and reward perception (Wang \& Griskova-Bulanova, 2018), short sleep duration (ElSalhy et al., 2019), and unhealthy behaviours (Shang-Yu Yang et al., 2019) as these symptoms indicate an increased risk of developing or suffering from GIA.

According to J. Tang et al. (2014), the risk of GIA decreased with age, whereas ElSalhy et al. (2019) found it to increase with age. The sample in the study of ElSalhy et al. (2019) were aged from 9-25 years, whereas the participants in J. Tang et al.'s study (2014) were in junior and senior high school (mean age $_{15} 15.4$ years, $S D=1.7$ years). It might be natural for senior high school to be more academically demanding, leaving less time for leisurely computer use, which could explain the opposite association between age and GIA. Other studies such as that by Seki et al. (2019) and Turel et al. (2015) also describe university students as an at-risk group, supporting ElSalhy et al.'s findings (2019).

According to the studies included in this review, self-harm behaviours and suicidality are a prominent problem, as the risk of engaging in these behaviours is twice as high if GIA-criteria are met (H.-C. Liu et al., 2017; Pan \& Yeh, 2018). Both of these studies were conducted in Taiwan and examined self-harm behaviours and GIA in relatively large samples. However, data were collected some years ago, as H.-C. Liu et al. (2017) collected data in 2008-2009 and Pan and Yeh (2018) collected data in 2006-2008, whereas digital technology has developed rapidly within the last decade since the iPhone was introduced in 2007, smartphone use has become ubiquitous (Kuss, 2017), and is an intrinsic part of young people's lives which reinforces the self (Lopez-Fernandez et al., 2014). The significant association indicates a need of clinical attention, early intervention and further research into the generalisability of the results. Some of the weaknesses in the study by Gansner et al. (2019) are PIU having been measured through three binary items, and the 'Youth Risk Behavior Survey' (YRBSS, 2018) suicidal ideation survey is aimed at grades 9-12; however, participants as young as 12 years completed the measures.

Four studies investigated the association between GIA and aggression (Chamberlain et al., 2017; Gansner et al., 2019; Lim et al., 2015; Senormanci et al., 2014). Clinical parameters of anxiety, depression and impulsivity were mediating factors when aggression predicted GIA, but this was not the case when GIA predicted aggression (Lim et al., 2015). In the same study, adolescents suffering from GIA appeared to have more aggressive dispositions, putting them 
under increased risk of violence. The duration of Internet use and suppressed anger were found to predict GIA in a clinical sample (Senormanci et al., 2014). In addition hereto, according to Gansner et al. (2019), having an aggressive disorder significantly increased the risk of PIU. Chamberlain et al. (2017) discovered that compared to gamblers without PIU, gamblers with PIU reported lower quality of life, lower self-esteem, elevated rates of intermittent explosive disorder and post-traumatic stress disorder (PTSD), and deficits in decision-making and spatial working memory.

The assessed studies indicate associations between GIA and aggression (Chamberlain et al., 2017; Gansner et al., 2019; Lim et al., 2015; Senormanci et al., 2014). Aggression (Chamberlain et al., 2017; Gansner et al., 2019; Lim et al., 2015) and suppressed anger (Senormanci et al., 2014) appear to be significant risk factors for GIA in adolescents and adults, and this might be explained in part by clinical factors of depression, anxiety and impulsivity (Lim et al., 2015). In a clinical sample, Chamberlain et al. (2017) found the GIA subjects to suffer from problems with aggression, and lower self-esteem and quality of life. A weakness in the studies by Chamberlain et al. (2017) and Senormanci et al. (2014) are sample sizes; in Chamberlain et al.'s study (2017), 18\% participants were in the PIU group, and the study by Senormanci et al. (2014) involved a clinical sample consisting of only 40 subjects.

Three studies that explored the connection between sleep and GIA met the inclusion criteria (ElSalhy et al., 2019; Kawabe et al., 2019; P.-H. Lin et al., 2019). These studies found IA was significantly associated with poor sleep quality (P.-H. Lin et al., 2019), sleep problems (Kawabe et al., 2019) and were negatively associated with sleep duration (ElSalhy et al., 2019). The studies presented here on GIA and sleep found positive associations between severity of GIA and sleep problems (ElSalhy et al., 2019; Kawabe et al., 2019; P.-H. Lin et al., 2019) and this finding is relevant as sleep duration and sleep hygiene is important for psychological wellbeing especially in adolescents (Medic, Wille, \& Hemels, 2017).

GIA was also explored in Japanese adolescents suffering from ADHD, ASD or comorbid ADHD and ASD (So et al., 2017, 2019). Scores for overall functioning and school grades were significantly correlated with IAT in the comorbid ASD and ADHD group. At follow-up, remission was $60 \%$ and incidence was $5 \%$; however, the prevalence rate only decreased from $12.9 \%$ (So et al., 2017) to $11.2 \%$ (So et al., 2019). According to the authors, the results are similar to other studies using general populations (So et al., 2019). 


\subsubsection{GIA Interventions}

Similarly to the samples exploring the characteristics and risk factors of GIA, most samples consisted of students, apart from the study by Young (2013) in which participants were 22-56 years old. Nine studies assessed interventions for GIA. Two prevention studies used community samples (Turel et al., 2015; Sun-Yi Yang \& Kim, 2018) and seven intervention studies used clinical samples (Bipeta et al., 2015; Erden \& Hatun, 2015; Khazaei et al., 2017; S.-H. Kim et al., 2018; Q.-X. Liu et al., 2015; Y. Yang et al., 2017; Young, 2013). The case study by Erden and Hatun (2015) involved a 14-year-old Turkish girl, whose IAT score was 81 pre-treatment. Based on the K-Scale, S-H. Kim et al. (2018) identified 17 adolescents with GIA (58.8\% females) from an industrial high school and a female middle school, who made up their sample. Y. Yang et al. (2017) divided a clinical sample of Chinese young adults (YDQ $\geq 5,89.7 \%$ males) into two experimental groups $(n=14, n=15)$, and compared them to a healthy control group $(n=16)$. Khazaei et al. (2017) divided 48 Internet addicted university students (IAT $\geq 50$ ) into an experimental group and waitlist control group. A total of 38 Indian adult obsessive compulsive disorder patients (OCD) made up the sample in the study by Bipeta et al. (2015), alongside an aged-matched control group of 34 healthy individuals; $29 \%$ OCD subjects suffered from GIA at baseline (YDQ $\geq 5)$. A total of 79 South Korean middle school students $(51.9 \%$ males) consisted of an experimental group $(n=38)$ from one school and a control group ( $n=41)$ from another school (Sun-Yi Yang \& Kim, 2018), and based on the IA proneness scale (K-Scale) (Korean National Information Society Agency, 2013), prevalence rates for possible addiction were $15.8 \%$ and $26.8 \%$ (these numbers were not statistically significantly different from each other). Q.-X. Liu et al. (2015) split a clinical group of Chinese adolescents $(n=46)$ and their parents $(n=46)$, recruited through advertisements on school websites, into an experimental group and a waitlist control group. Based on the Adolescent Problematic Internet Use Scale (APIUS), 91\% of the experimental group met the measurement criteria at baseline. A total of 128 American participants suffering from IA (YDQ $\geq 5,65 \%$ males) were recruited by Young (2013); twelve participants who met just four of the criteria were also included due to serious problems caused by GIA. The study by Turel et al. (2015) involved an American sample of 233 university students from Health Science and Business (60.9\% females). In spite of using a 14-item IA measurement (van Rooij et al., 2011), the authors did neither report the prevalence rate before nor after the intervention.

The present review identified nine intervention studies on GIA (Bipeta et al., 2015; Erden \& Hatun, 2015; Khazaei et al., 2017; S.-H. Kim et al., 2018; Q.-X. Liu et al., 2015; Turel et al., 2015; Sun-Yi Yang et al., 2019; Y. Yang et al., 2017; Young, 2013), and two studies 
exploring perceptions of interventions (O'Brien et al., 2016; Shahrbabaki et al., 2017) which are clustered by the type of interventions in use. In an experiment to show instructive videos' effect on attitudes towards Internet addiction in a 'high risk'-community sample of university students, 'video 1' was informative and included surprising findings, whereas 'video 2' was found on Youtube, explaining GIA in a humorous, but less informative and surprising manner (Turel et al., 2015). A group of health science students watched video 1, and group of business students watched video 2. The informative video improved the students' attitudes towards reducing their Internet use, and therefore appeared to be a useful act of prevention. Turel et al. (2015) showed that GIA is a growing problem in university students, causing social, personal, work and school problems, and that prevention is cheaper than treatment, which are reasons why it is of importance to explore preventive actions. According to Turel et al. (2015) the informative video group improved their attitudes towards Internet use; however, no results are reported on whether PIU decreased.

Several studies used group-based interventions; one of these is a school-based preventive intervention using a self-regulatory efficacy improvement programme, consisting of a weekly session of group activities, peer support, group education, role play, empathic communication and physical activities, appeared to improve self-control, self-efficacy, Internet addiction and Internet usage time in the students based on self-report measures (Sun-Yi Yang \& Kim, 2018). Another group treatment approach used a school-based CBT programme which reduced Internet usage and scores on IAT, depression and state anxiety significantly (S.-H. Kim et al., 2018). Similar results were found by Q.-X. Liu et al. (2015), who offered manualized multifamily group therapy to their experimental group; Internet use time fell, and based on the APIUS scale, the experimental group went from having 21 Internet addicted adolescents to one after the intervention, two subjects experiencing relapse at the 3-month follow-up. The majority $(96 \%)$ of the control group were still addicted after the intervention. In the group intervention implemented by Khazaei et al. (2017), the experimental group received a positive psychology group intervention, following which scores on the IAT in that group decreased, and social adjustment improved. Similarly, IAT and impulsivity scores decreased after an intervention, in which one group received a psychological intervention of CBT and another electroacupuncture (EA); the change was more prominent in the EA-group (Y. Yang et al., 2017).

Of the studies with more individual approaches, the study by Erden and Hatun (2015) provided a 14-year-old girl affected by GIA with seven sessions of CBT. Her social relations improved, and the IAT score dropped from 81 to 48. Young's (2013) participants also received CBT for Internet addiction, (CBT-IA). The majority of patients were able to fully manage their 
symptoms by the $12^{\text {th }}$, and last, session. Bipeta et al. (2015) worked with a group of 38 OCDpatients (eleven IA subjects) and a control group ( $n=34$, three IA subjects), and after one year of pharmacological treatment for OCD in the clinical group, Yale-Brown Obsessive Compulsive Scale (YBOCS) scores decreased, and out of the group of 38 OCD-patients, the number of subjects with IA dropped from eleven to two.

O'Brien et al. (2016) explored PIU students' views on treatment through a mixed methods study through focus groups and surveys. Two themes emerged, readiness to change, where Internet overuse is so common that seeking treatment is unnecessary, and second, receptivity to treatment, where the sample was hesitant and ambivalent. In the study by Shahrbabaki et al. (2017), focus groups, interviews and drawings explored the multidimensional needs of students for IA prevention. Four categories emerged: 1) social support, 2) personal competence, 3) appropriate culture, and 4) maintenance and improvement of health.

To summarize the interventions to prevent and treat GIA, interventions resulted in a decrease in GIA scores. Group therapy interventions (Khazaei et al., 2017; S.-H. Kim et al., 2018; Q.-X. Liu et al., 2015; Y. Yang et al., 2017; Sun-Yi Yang \& Kim, 2018) and individual approaches (Erden \& Hatun, 2015; Young, 2013) appeared successful. Moreover, electroacupuncture (Y. Yang et al., 2017) and pharmacological treatment (Bipeta et al., 2015) also improved GIA symptoms, and in Y. Yang et al.'s study (2017), electro-acupuncture was superior to the psychological intervention; however, both provided statistically significant results. When asked in qualitative studies, focus groups of students reported that preventions should aim to improve and implement social support, personal competence, health and appropriate culture in the shape of education and moral values (Shahrbabaki et al., 2017), and treatment interventions were challenged by Internet overuse being perceived as a normal and common issue amongst students (O’Brien et al., 2016).

Not only PIU improved with the implemented interventions, levels of control and impulsivity (Bipeta et al., 2015; Y. Yang et al., 2017), social relations and adjustment (Erden \& Hatun, 2015; Khazaei et al., 2017), depression and anxiety scores (S.-H. Kim et al., 2018) also improved in the samples. This indicates the intricate nature of the phenomenon and the close linkages to lack of wellbeing, problematic social relations, and impulsivity problems. 


\subsection{Online Gaming Addiction}

The research included in this systematic literature review included 25 online gaming addiction studies and focused on risk factors and development and validation of measurements, and on intervention studies.

\subsubsection{Risk Factors}

A total of 14 cross-sectional correlation studies were identified, four of which used community samples. S.-Y. Lee et al. (2018) included 60 South Korean adolescent patients who had visited addiction or child- and adolescent clinics (80\% males), and after six months, 31 participants remained. Dufour et al. (2019) recruited 80 Canadian adolescents (93.8\% males), who had contacted one of 13 Addiction Treatment centers. The study by Cole and Hooley (2013) included 163 adult American massively multiplayer online (MMO) players (58.6\% males); PIU was evaluated with the Generalised Problematic Internet Use Scale (GPIUS) score that had no published cut-off score. The study by Yeh et al. (2017) included a sample of Chinese adults suffering from IGD and 87 control subjects ( $80.5 \%$ males in both groups). In the study by King et al. (2018), 186 Australian adult treatment seekers participated, who had voluntarily sought help on the website Game Quitters. Jo et al. (2019) had a clinical sample counting 188 South Korean adolescents (75.5\% males). Koo et al. (2017) recruited 236 South Korean adolescents from community and clinical settings, and in the sample the prevalence was $10.8 \%$ based on the K-Scale. Jeong et al. (2018) included 45 South Korean adolescents with IGD and 228 normal controls (54.9\% males). The South Korean sample of adolescents in the study by Seong et al. (2019) consisted of 152 problematic gamers (90.8\% males), 138 frequent gamers (88.4\% males), and 139 infrequent gamers (89.2\% males) recruited using the IAT. In the crosssectional study by J. Y. Kim et al. (2017), 1.654 South Korean elementary and middle school students (52\% males) completed surveys, measuring online gaming addiction using a modified version of the IAT (S. Y. Lee \& Kwon, 2001). Also involving a South Korean sample was the study by $\mathrm{Na}$ et al. (2017) who recruited 1.819 adult participants (52.7\% males), who completed a web-based survey. IGD was measured using the nine DSM-5 criteria and showed a prevalence of $14.1 \%$. The study by Sul (2015) also used a South Korean community sample of adolescents, and 3.356 responses were usable for analysis (no demographics reported). Out of the twelve studies presented above, eight were conducted in South Korea (Jeong et al., 2018; Jo et al., 2019; J. Y. Kim et al., 2017; Koo et al., 2017; S.-Y. Lee et al., 2018; Na et al., 2017; Seong et al., 2019; Sul, 2015). The community samples (Cole \& Hooley, 2013; J. Y. Kim et 
al., 2017; Na et al., 2017) had a more even gender distribution (52-58.7\% males), whereas the clinical samples consisted of 54.9-93.8\% males.

To summarize the findings presented in this section, depression (Cole \& Hooley, 2013; Dufour et al., 2019; King, et al., 2018; Na et al., 2017; Seong et al., 2019) and aggression (Jeong et al., 2018; J. Y. Kim et al., 2017; S.-Y. Lee et al., 2018; Na et al., 2017) were major risk factors for online gaming addiction. In addition, the severity of gaming problems was associated with comorbid complications, such as suicidality (Jeong et al., 2018), anxiety (Cole \& Hooley, 2013; Jeong et al., 2018; Ryu et al., 2019; Seong et al., 2019), impulsivity/ADHD (Na et al., 2017; Seong et al., 2019; So et al., 2019), harm avoidance (S.-Y. Lee et al., 2018; Seong et al., 2019), and procrastination (Yeh et al., 2017b).

Similar to the studies on GIA, mood symptoms were common features in the following online gaming addiction studies. Cole and Hooley (2013) defined problematic Internet use as gaming problem in the context of MMO gaming in American adults. They found that high PIU was associated with higher levels of social phobia, state and trait anxiety, introversion, neuroticism, and absorption. In Canadian adolescents with PIU, 97.5\% of the adolescents in the sample suffered from a comorbid mental health disorder, $92.6 \%$ felt their Internet use challenged family relationships, and 50\% reported it impeded their social relationships (Dufour et al., 2019). In a study identifying variables predictive of this short-term commitment to abstain from gaming for a week, participants with mood symptoms generally scored higher on IGD and on the gaming cognitions scale, had worse quality of life and found it harder to abstain from gaming for a week (King, et al., 2018). Seong et al. (2019) similarly discovered that compared to frequent gamers and controls, their problematic gaming group scored significantly higher on harm avoidance, novelty seeking and reward dependence. Furthermore, scores on depression, anxiety, and ADHD were highest in the problematic gaming group. Suicidality was also explored by Jeong et al. (2018) in their sample of South Korean adolescents; the prevalence of suicidality in IA subjects was $32 \%$ compared to $13 \%$ in the non-IGD group. Scores were also significantly higher in the IGD-group on anxiety and aggression, and lower for self-esteem and familial support.

Regarding aggression, a risk factor for GIA, S.-Y. Lee et al. (2018) investigated the clinical course of IGD in youths and found the non-improvers in their sample had higher scores on harm avoidance and aggression at baseline. In a community sample, adolescents from lowincome families were more likely to experience child abuse, be perpetrators of school violence, be addicted to online games, and suffer from low self-esteem (J. Y. Kim et al., 2017). Furthermore, males with lower academic performance were more likely to behave violently (J. 
Y. Kim et al., 2017). In a community sample of South Korean adults, clinical psychopathologies, Internet game usage patterns of IGD and Alcohol Use Disorder (AUD) were investigated, and the comorbidity group had substantially more clinical features including impulsivity, impaired self-control, and mood symptoms than either IGD or AUD only (Na et al., 2017).

Yeh et al. (2017) evaluated the association between procrastination and IGD, and after controlling for depression, hostility, and impulsivity, procrastination was still found to be associated with IGD. Sul (2015) found male adolescents were more prone to IGD and family leisure activities effective in decreasing IGD.

Two studies used samples of subjects with online gaming addiction (P. W. Kim et al., 2013; C.-H. Lin et al., 2019). P. W. Kim et al. (2013) investigated how a course in writing and speaking using narrative characteristics and content from Massively Multiplayer Online RolePlaying Games (MMORPGs) 'Dungeon and Fighter' influenced language expression and gaming addiction. Participants in the experimental group improved their writing and speaking ability far more than those in the control group.

C.-H. Lin et al. (2019) examined the validity of the clinical Iowa Gambling Task (IGT) by comparing performances of controls with cases of IGD. They found no statistical difference between the clinical sample and the healthy controls on the IGT, which is surprising as impulsivity has consistently been found to be associated with IGD. The first of these two studies found gaming-related content made a difference to the desired outcome and improved the writing and speaking ability more than in the control group, who worked with other materials. This might underline the salience of the gaming universe to individuals absorbed in MMORPGs. The second study found no statistical difference between IGD cases and the control group, signifying either there are no significant differences in choice behaviour between the two groups, or that the IGT is not an appropriate measure to reveal such differences.

This systematic literature review identified three studies which validated and evaluated measurements for diagnosing online gaming disorder. Jeong et al. (2018) aimed to estimate overreporting and underreporting rates in self-reported compared to clinically diagnosed individuals with IGD; the false-negative rate (sensitivity) for self-reported IGD assessment was $44 \%$, and the false-positive rate (specificity) was 9.6\%. The DSM-5 criteria and the ICD-11 were explored by Jo et al. (2019). The combined group that met not just the criteria of the DSM-5, but also the ICD-11, had significantly higher rates of depression, oppositional defiant disorder and conduct disorder, and their gaming debut occurred at an earlier age and they spent 
more time gaming during the week. ADHD was the most common disorder in all groups. The aim in Koo et al.'s study (2017) was to develop and validate a structured clinical interview for IGD. The Clinical Structured Interview for IGD (CSI-IGD) had a sensitivity of 57.1 and a specificity of 95.9, which according to the authors makes it a 'useful test' for identifying the absence of IGD and a 'very useful test' for identifying IGD. The ICD-11 criteria were substantially more difficult to meet than the DSM-5 criteria, presenting risks of underreporting cases of gaming addiction; however, focusing on more severe cases in greater need of treatment. The findings of the study by Jo et al. (2019) support the previous findings that depression (Cole \& Hooley, 2013; Dufour et al., 2019; King et al., 2018; Na et al., 2017; Seong et al., 2019) and aggression (J. Y. Kim et al., 2017; S.-Y. Lee et al., 2018; Na et al., 2017) often co-occur with gaming addiction.

\subsubsection{Gaming Addiction Interventions}

Overall, the interventions had a positive effect on IGD symptoms (D. H. Han et al., 2018; X. Han et al., 2018; Kang et al., 2018; W. Li et al., 2018; S. Y. Park et al., 2016; Yao et al., 2017), depression (D. H. Han et al., 2018; X. Han et al., 2018; Kang et al., 2018), impulsivity (D. H. Han et al., 2018; X. Han et al., 2018) and self-efficacy (Sakuma et al., 2017). Similarly to the intervention studies targeting IA, the treatments on gaming addiction used group treatment. CBT was a common approach and was used in more than half of the above mentioned treatments (D. H. Han et al., 2018; X. Han et al., 2018; S. Y. Park et al., 2016; Sakuma et al., 2017). Kang et al. (2018) and Sakuma et al. (2017) both used camps in which young people were together for a week with a screen-free schedule of therapeutic activities and free time, during which they socialised, indicating that the therapeutic approach was only one of several other variables affecting participants, thereby making it impossible to isolate treatment effects. Other approaches to therapy such as virtual reality treatment (S. Y. Park et al., 2016) and mindfulness-based practices (Li et al., 2018; Yao et al., 2017) appeared effective in reducing IGD symptoms.

Eleven of the studies included in the current review are intervention studies focusing on gaming addiction specifically. Samples, methods and findings are presented subsequently. Two qualitative case studies involved a single family; T. Y. Park et al. (2014) involved a 23-year old South Korean male and his family of father, mother and brother, and Yu and Park (2016) assessed a South Korean family of mother (age 57), and two brothers (age 30 and 32). Sakuma et al. (2017) included ten Japanese male adolescents affected by IGD, and in the study by X. 
Han et al. (2018) 26 male Chinese IGD adolescents took part. Kang et al. (2018) recruited 15 South Korean adolescent males with insecure attachment styles and possibility for IGD and a healthy control group of 15 male adolescents with secure attachment styles. A total of 30 American IGD-affected subjects (80\% males) participated in the study by W. Li et al., (2018). In the study by S. Y. Park et al. (2016), the clinical sample consisted of 24 South Korean male adults affected by online gaming addiction, and a control group of twelve male casual gamers. Yao et al. (2017) recruited 25 Chinese IGD adults, and a control group of 21 healthy individuals (no information on sex distribution). In the study by Apisitwasana et al. (2018), two Indian primary schools were randomly assigned to an intervention ( $n=148,51.7 \%$ females) and control group ( $n=159,58.5 \%$ males). In the study by A. Y. Li et al. (2019) 39 primary schools in Hong Kong agreed to participate and were randomly assigned to an intervention ( $n=163$ parents, 77\% females, and children, 63.2\% males), and a control group ( $n=199$ parents, 83\% females, and children, 60.8\% males). D. H. Han et al. (2018) examined 367 South Korean adolescents and adults $(95.2 \%$ males) treated for IGD within the previous five years and who took part in the follow-up study.

Five out of eleven studies, took place in South Korea (S. H. Han et al., 2018; Kang, et al., 2018; S. Y. Park et al., 2016; T. Y. Park et al., 2014; Yu \& Park, 2016). The samples were male dominated, with four studies intervening on all-male samples (X. Han et al., 2018; Kang, et al., 2018; S. Y. Park et al., 2016; Sakuma et al., 2017). Apart from the studies using community samples (Apisitwasana et al., 2018; A. Y. Li et al., 2019), the clinical samples consisted of 80$100 \%$ males.

Regarding interventions, CBT was administered. The sample in D. H. Han et al.'s study (2018) completed eight weeks of CBT and any comorbid diseases were medicated. The need for further treatment was predicted by IA, depression and ADHD scores, with these three factors complicating treatment course. The adolescent sample in the study by X. Han et al. (2018) also received $\mathrm{CBT}$ with their parents and teachers. Before and after the intervention, they were screened for comorbid disorders and scanned using resting state functional Magnetic Resonance Imaging (fMRI). After the treatment programme, the IGD subjects showed significantly improved scores on the scales measuring IA, anxiety, depression and impulsivity, and the amplitude of low frequency values (ALFF) was significantly lower in the left medial orbitofrontal cortex (OFC) and the putamen. In the study by S. Y. Park et al. (2016), CBT was investigated in comparison to virtual reality treatment (VRT), aiming to induce aversion to gaming-related cues. After the four-week treatment period, the fMRI-assessments showed increased connectivity from the posterior cingulate cortex (PCC) seed to the left middle frontal 
and bilateral temporal lobe in the VRT group, and IA scores decreased significantly in both groups. Sakuma et al. (2017) implemented a Therapeutic Residential Camp, in which the treatment consisted of 14 sessions of CBT, three medical lectures and eight personal counselling sessions and a workshop, and digital devices were not allowed during the camp. Three months after the Self-Discovery Camp, Internet use time was significantly reduced, and self-efficacy had improved.

Another sample measured using resting state fMRI was a group of adolescent males with insecure attachment styles and possibility for IGD in the study by Kang et al. (2018). After a week of staying in a camp together and participating in equine-assisted activities and therapy, IA scores decreased, the functional connectivity in the affective networks was improved in the IGD group, and their avoidance and depression scores also improved.

Two studies implemented mindfulness practices, one of which included W. Li et al. (2018) introducing Mindfulness-Oriented Recovery Enhancement (MORE). The authors found that a reduction in IGD symptoms was mediated by changes in maladaptive gaming-related cognitions. MORE enhanced positive appraisal significantly more than the parallel support group intervention. Yao et al. (2017) implemented a group behavioural intervention combining reality therapy and mindfulness. The results revealed the IGD group showed more risky decision-making than the healthy controls both before and after the intervention. However, their delay discounting rate and IGD severity improved with the intervention.

Apart from completing questionnaires to assess treatment outcomes, three studies investigated their participants further using fMRI scanning (X. Han et al., 2018; Kang, et al., 2018; S. Y. Park et al., 2016). These studies found functional connectivity increased and improved in IGD subjects post-treatment. Yet again, the interventions had a positive effect on gaming addiction, and the exact approach appears to be of lesser importance.

Two studies investigated IGD interventions in community samples. Apisitwasana et al. (2018) trialled a school- and family-based intervention programme. The 8-week programme entailed a weekly hour of teacher-led activities, and parents were to maintain consistency throughout. After the intervention, the experimental group spent significantly less time gaming, and knowledge, attitude and self-regulation significantly improved. A. Y. Li et al. (2019) implemented a parent-based "Game Over" intervention on gaming addiction in primary school children. The intervention group received 4-hour training split into three modules on parental monitoring, parental care and psychoeducation, whereas the control group received a 4-hour two-module training on learning techniques and learning styles. In both the intervention group and the active control group, the children decreased their gaming time, exposure to violent 
video games and symptoms of gaming disorder. According to the authors, the change was larger in the intervention group; however, their symptoms of gaming disorder were also more severe at baseline. In these two intervention studies it was shown once more that intervening on gaming addiction makes a difference; A. Y. Li et al.'s study (2019) is a good example that the intervention group and the control both improved significantly in spite of receiving different interventions. Both approaches were effective for gaming addiction, as the environment surrounding the child got involved in improving their self-regulation and gaming behaviour.

Two studies were conducted as qualitative case studies, involving the family. T. Y. Park et al. (2014) conducted a qualitative case study on a 23-year old South Korean male and his family of father, mother and brother. The study examined the effectiveness of 15 treatment sessions, and the authors found dysfunctional communication patterns and characteristics of the parents' families had led to interpersonal problems in the young man. Improving awareness of these problems was a problem-solving factor. Likewise, Yu and Park (2016) assessed a young male's reaction to treatment for symptomatic problems with bullying and gaming addiction, involving the family. Dysfunctional communication patterns were identified, and the effectiveness consisted of changes in communication methods and perceptions and a better selfdifferentiation, improving the individual's ability to discern between thoughts and feelings (Yu \& Park, 2016). These two studies presented above followed the same approach; both were South Korean studies offering treatment to an individual and his close family, making use of Bowenian Theory and the Mental Research Institute Family Therapy Model. In both cases, problems stemmed from dysfunctional communication patterns with parents and their family relationships.

\subsection{Online Gambling Addiction}

In the studies assessed, severe gambling problems were associated with lower emotional intelligence (Parker et al., 2013) and psychological distress (Gainsbury et al., 2015). The above and Chamberlain et al.'s study (2017) were all conducted in Western countries. Three studies (Gainsbury et al., 2015; Harris \& Mazmanian, 2016b; Parker et al., 2013) explored characteristics related to online gambling disorder, and one study (Harris \& Mazmanian, 2016a) explored the effect of CBT for Internet gambling behaviour; the four studies used clinical samples. Gainsbury et al. (2015) examined differences in characteristics in Internet gamblers with single or multiple online gambling accounts in a cross-sectional online survey 
completed by 3.178 Australian gamblers ( $85.5 \%$ males). Half of the gamblers holding multiple accounts had at least moderate gambling problems, whereas less than a third of the single account holders experienced these problems. Having multiple accounts was also associated with higher psychological distress scores. Parker et al. (2013) explored the relationship between adolescent problem gambling, Internet use, and video game playing in a sample of 270 Canadian adolescent clinical outpatients (66.7\% males) and 256 special needs students (62.5\% males), and dysfunctional preoccupation accounted for half of the variability of addiction-related behaviours. Emotional intelligence predicted gambling problems, Internet abuse, or computer game misuse.

The first study by Harris and Mazmanian (2016a) explored the effect of a group CBT programme for problem Internet gamblers. The group of self-identified Internet gamblers was divided into a treatment group and a waitlist control group, and at post-intervention assessment, the subjects improved on DSM-IV criteria for pathological gambling, perception of control over gambling and number of sessions gambled. At three months follow-up, desire to gamble had also significantly improved.

The qualitative second study by Harris and Mazmanian (2016b) assessed perspectives on treatment experiences provided by 24 Canadian self-identified problem gamblers. The openended questions resulted in five themes: Internet gambling accessibility as a means to stop gambling behaviour, a lack of alternative activities and stress, the importance of behavioural strategies in reducing Internet gambling behaviour, motivational interviewing and motivation for change in early treatment, and support from other group members. These qualitative and quantitative findings may lead the way forward as inspiration for future interventions in the field. According to Harris and Mazmanian (2016b), treatment should focus on reducing accessibility to gambling sites, alternative activities, behavioural strategies, motivational interviewing and group support.

\subsection{Online Pornography Addiction}

Only two studies on pornography addiction met the inclusion criteria for this review (Crosby \& Twohig, 2016; Short et al., 2016). The intervention study by Crosby and Twohig (2016) recruited a clinical sample of 28 males, all but one members of the Church of Jesus Christ of Latter-day Saints. They were divided into an intervention group who received individualised Acceptance and Commitment Therapy (ACT), and a waitlist control condition who received treatment after 12 weeks. When combining the two groups upon treatment completion, the 
authors found a $92 \%$ reduction in Internet pornography use, amounting to $86 \%$ at 3 -months follow-up. The implemented intervention differs from many of the other interventions presented in this review, as individualised treatment was offered instead of group therapy. The authors mention the potential of involving the participant's spouse or partner, but confidentiality must be secured as online pornography addiction is associated with a higher degree of taboo than the other digital addictions.

In the study by Short et al. (2016), American mental health professionals (MHP) completed surveys to explore how sex addiction and problematic Internet pornography (IP) use present to MHP and how they conceptualise and treat these problems. MHPs indicated sexual addiction and problematic IP use are most frequently related to relationship problems, disruptive preoccupation, and behavioural dyscontrol, and they also reported high rates of psychiatric comorbidity in clients with problematic sexual behaviours.

\subsection{Social Media Addiction}

Only one intervention study included in this review focused on social media addiction. Manwong et al.'s (2018) intervention study in a community sample of Thai high school students used an 8-week group activity-based motivational enhancement therapy programme. This approach was similar to the intervention studies on gaming in community samples (Apisitwasana et al., 2018; A. Y. Li et al., 2019), incorporating the intervention into the school day. According to the results presented in the article, both the experimental and the control group showed unchanged or slightly increased time spent on social media, emotional behaviour, and depression scores. The authors highlighted that the intervention group's depression scores did not increase as much as the control group scores, which increased markedly, but as the adolescents involved did not appear to spend less time on social media after the intervention, and their depression scores increased too, the intervention was not recommendable.

\section{General Discussion}

The aims of the present review were to (i) highlight the main findings in explorative and intervention studies, and (ii) to investigate the cultural similarities and differences within the extra-European regions. To the authors' knowledge, the present study is the first to review all available studies on IA published outside of Europe since April 2013, when IGD was included in the DSM-5. In correspondence to the recent systematic literature review of European studies on IA issued within a corresponding timeframe (Lopez-Fernandez \& Kuss, 2019, 2020), this 
review examined the most striking similarities and differences within and across cultures. A total of 64 empirical studies were included, focusing on GIA, online gaming, Internet gambling, Internet pornography addiction, and social media addiction. The studies focused on exploring the characteristics and the risk factors connected to online addictions, and intervention studies employed to prevent or treat the respective addiction.

Regarding risk factors, the included studies consistently found GIA was most often accompanied by psychological comorbidities and lack of mental wellbeing. One of the most commonly co-occurring mental disorders was depression, which was up to more than seven times more likely if the comorbid GIA was severe (Seki et al., 2019). Adolescent depression has been associated with major depression, anxiety disorder, and substance abuse in adulthood (McLeod et al., 2016), and subclinical depressive symptoms in early adolescence are associated with poorer quality of romantic relations and greater loneliness in adulthood (Allen et al., 2014). These findings indicate preventing adolescent depression and mental health problems is of critical importance for the wellbeing and life quality of young people.

Based on the results presented in this review, a substantial proportion of students in high school and university suffer from problems related to their Internet use; not just depression, but a range of comorbid disorders. According to Lopez-Fernandez and Kuss (2019, 2020), anxiety, depression, and OCD were frequently observed with GIA in European samples, and these comorbidities appeared the norm rather than the exception in international clinical samples (Kuss \& Lopez-Fernandez, 2016) in regards to GIA and IGD. According to King et al. (2012), university students might be particularly vulnerable to online addictions as they often have flexible tuition and could suffer from multiple stressors associated with settling in a new context.

Self-harm behaviours and suicidality were connected to GIA, the prevalence of GIA being twice as high in adolescents engaging in self-harm behaviours (H.-C. Liu et al., 2017) and the risk of developing self-harm behaviours being more than twice as high if diagnosed with GIA (Pan \& Yeh, 2018), both results highlighting the need for early interventions. With the relative risk of suicide increasing with multiple incidents of self-harm and an inverse relation to age, the association between self-harm and GIA should be investigated further cross-culturally.

Aggression was also a risk factor for GIA, particularly when anger was suppressed (Senormanci et al., 2014), or when aggression was mediated by anxiety, depression and impulsivity (Lim et al., 2015). Subjects affected by GIA are more likely to be predisposed to aggression, and thereby at increased risk of experiencing violence (Lim et al., 2015), which may result in more harm caused by or against these individuals. A similar finding was reported 
in a study by Festl et al. (2013) in a German sample, aggression was more prominent in the adolescents compared to the older participants, resulting in increased risk for younger problematic computer game users.

Lack of sleep due to mobile phone use was reported in the review on European research by Lopez-Fernandez and Kuss (2019), and in the current review reduced sleep duration was accompanied by poor sleep quality as a reported problem amongst subjects suffering from GIA. It is likely that PIU leads to insufficient and poor-quality sleep (Alimoradi et al., 2019), and that chronic sleep loss in turn leads to increased risk of GIA; similarly to the bidirectional association that has been identified between sleep problems and alcohol consumption (Owens et al., 2014). Insufficient sleep poses serious risks to physical and emotional health, academic success and safety (Owens et al., 2014), and consequences include reduced quality of life, emotional distress, and mood disorders (Medic et al., 2017), all of which may have detrimental effects on everyday life and wellbeing. The associations between GIA, aggression and sleep disruption were not reported in regards to IGD, gambling addiction, IP addiction and social media addiction; an important next step in future studies is to investigate these connections in order to clarify the similarities and distinctions between GIA and the specific online addictions (Davis, 2001; Montag et al., 2015; Lopez-Fernandez, 2018).

Furthermore, the studies included in this review highlighted additional dysfunctions associated with comorbidities with online addictions, such as alcohol use disorder (Na et al., 2017), OCD (Bipeta et al., 2015), ADHD and ASD (So et al., 2017, 2019). Attention should be paid to these comorbidity groups, as psychopathological impairments were more severe than being affected by either disorder alone.

The studies that used neuroimaging such as fMRI or ERP (D. H. Han et al., 2018; Hou et al., 2019; Kang et al., 2018; P. W. Kim et al., 2013; S. Y. Park et al., 2016) consistently found GIA associated with reduced activity in prefrontal regions, weakened inhibitory networks, affective networks and reward processing. Similar symptoms of reduced frontal activity have consistently been associated with substance abuse (Goldstein \& Volkow, 2002; Kalivas \& Volkow, 2005) and support the definition of GIA as a behavioural addiction. Interventions increased frontal connectivity (Kang et al., 2018; S. Y. Park et al., 2016), thereby potentially altering the neurological mechanisms behind addiction.

In terms of interventions, it was reported CBT leads to significant changes in GIA symptoms (Lopez-Fernandez \& Kuss, 2019); however, the intervention studies included in this review appeared effective in reducing the symptoms of GIA regardless of the treatment approach. The majority of the treatment studies were based on CBT (Kuss \& Lopez-Fernandez, 
2016); however, positive psychology interventions (Khazaei et al., 2017), electro-acupuncture (Y. Yang et al., 2017), virtual reality treatment (S. Y. Park et al., 2016) and pharmacological treatment (Bipeta et al., 2015) improved GIA symptoms and thereby reduced IAT scores in the specific samples.

Most interventions were directed at adolescents and had a group-based approach, involving parents, teachers, and students. Engaging adolescents in leisure activities and group therapy reduced GIA symptoms, time spent online and symptoms of comorbidities, such as impulsivity, depression, and anxiety levels improved alongside social relations and self-efficacy. Preventions took the shape of e.g. watching informative videos, effective in improving the students' attitudes to Internet use (Turel et al., 2015), and others were school-based, involving and training parents, successful in reducing gaming time and improving knowledge and selfregulation. The group-based approaches added several variables difficult to measure, such as new social relations and alternative activities to screen time. One way to address this is to recruit a control group of GIA subjects who take part in the social aspects, but not the therapy itself, similar to A. Y. Li et al.'s study (2019), alongside a control group not involved in any interventions.

Another variable connected to online addictions is time spent on the online activity, and this was conceived as a defining element by P. W. Kim et al. (2013) who stated because IGD correlates with time spent playing computer games, their IGD measurement was based on game time, and gaming addiction was defined as as $>4 \mathrm{~h}$ game play per weekday. Following the definition proposed by these authors, the majority of the subjects affected by GIA according to e.g. Jeong et al. (2018) and Lim et al. (2015) would not have been identified, as the average time spent by the PIU group was less than 4 hours per weekday. The study by Jeong et al. (2018) is a useful example that subjects can experience symptoms of IGD, although the amount of time spent playing is not excessive; the adolescents in the group of false negatives when assessed with the self-report spent an average of $132.7( \pm 81.3)$ minutes during weekdays compared to IGD-subjects spending an average of $215.2( \pm 132.9)$ minutes, and non-IGD subjects spent $65.1( \pm 85.5)$ minutes. This finding shows defining problematic gaming based on number of hours played appears to simplify a complex phenomenon, and should rather look at the effect of game play on the individual, taking into account the perception of the activity by the surrounding environment (e.g., friends, family, partner, home), and culture (Kuss, 2013; Lopez-Fernandez, 2018).

In their IGD review, King et al. (2017) recommend that the treatment follow-up period should be three to six months. The treatment studies employing follow-up measures included 
in this review generally completed the follow-up assessment at three months, similar to the European samples recently reviewed (Lopez-Fernandez \& Kuss, 2019, 2020); apart from S.H. Kim et al. (2018) who introduced the follow-up measure at one month, and Turel et al. (2015) conducted their follow-up assessment after one week. Completing a follow-up measure after such a short interval means possible intervention effects might not yet have subsided. A longer follow-up period is helpful to reveal potential long-lasting effects or lack thereof and to assess relapse incidents.

The studies with the lowest and highest prevalence rates using the same measure and cutoff reported GIA prevalence rates between $14.7 \%$ in Taiwanese female college students and $67.5 \%$ in a sample of South Arabian female nursing students. In comparison, Laconi et al. (2018) reported European prevalence rates to be between $14.3 \%$ in a German sample $(65.7 \%$ females) and 54.9\% in an English sample (76\% females), however the samples in this study varied from $2.7 \%$ to $99.6 \%$ females, and thereby were not representative of the population. According to Festl et al. (2013), differences in prevalence should not be assigned to cultural differences, but rather to differences in sampling populations; the reason prevalence rates in the samples were high may be due to adolescents not having obligations and work commitments in contrast to adults. A study by Liang et al. (2016) indicates depression leads Chinese adolescent boys to GIA, whereas GIA leads to mood disorders for their female counterparts.

Cross-cultural cross-study comparisons are further hampered by multiple translations of scales being used, resulting in subtle translation effects (Leong et al., 2003); however, it can be controlled through measurement invariance methods (Lai et al., 2015; Lopez-Fernandez, et al., 2019). Comparing across languages and cultures poses the dilemma of adjusting the scale to the specific culture without compromising the integrity of the test.

A prominent difference between the groups of individuals affected by GIA and IGD is GIA is more evenly spread across the sexes. As community samples often assess school and university students, these samples are divided more or less evenly overall. Similarly to the findings in a review on European studies (Lopez-Fernandez \& Kuss, 2019), problematic online behaviour is generally more prevalent in males compared to females; however, less so when it comes to GIA. Amongst the clinical samples, slightly more than half of participants with GIA were males (ca. 60\%), whereas for individuals with IGD, the vast majority are males (around $85 \%$ of the samples). The community samples recruited generally consisted of equal numbers of males and females when assessing GIA or IGD. The majority of the samples used in the studies examining online gambling and IP addiction were male. 
Only one study (Sakuma et al., 2017) of 30 included in the review on treatment of IGD by King et al. (2017) used DSM-5 IGD criteria; in the current review nine studies of 64 used these criteria; it is surprising that these criteria were not referred to more since the inclusion of the disorder in the DSM-5 manual in 2013.

Regarding cultural considerations, the majority of covered studies were published in South-East Asia ( $n=39,60.9 \%$ of the included studies). A total of 17 of these studies were South Korean, and according to Starcevic (2013) this might partly be because GIA is considered an issue of public health significance, but also because competitive online video gaming is heavily promoted, thereby "blurring the boundary between 'normal excessive' and pathologically excessive use of the Internet and online video games" (p. 16). Treatment centers have been established in South Korea and Japan in response to the growing public concern (Choi et al, 2018; Kuss, 2013; Koh, 2017; Lopez-Fernandez \& Kuss, 2019, 2020). With South Korea having implemented such a structured system in response to the online addiction problems (King et al., 2018), samples may be more readily available and research might even be funded by the government in those countries. Furthermore, easily accessible high-speed broadband has increased overall Internet use in South Korea compared to other countries with less advanced Internet (King et al., 2012). However, North America, and Europe have Internet penetration rates similar to or higher than most Asian countries, and a recent cross-cultural study (C. S. K. Tang et al., 2018) also found a higher IGD prevalence rate in a sample of United States (US) students than Asian students (Lopez-Fernandez, 2015). It might be relevant for further research to explore whether this is connected to cultural aspects of Western perspectives on gambling, and laws and opportunities for online gambling. According to Williams et al. (2013), the prevalence rate of problematic gambling in South Korea is low, because access is limited and perceptions on gambling are negative. However, overall more research is needed on gambling in Asian countries (Williams et al., 2013).

The occurrence of IGD might also be culturally connected to the style of upbringing; a study involving South Korean adolescents showed that symptoms of IGD were associated with poorer parental attachment, making parental factors an important predictive variable (K. Kim \& Kim, 2015). The study by Dufour et al. (2019) took a different perspective, and reported the majority of participants found their problematic Internet use harmed their family relations.

Regarding the use of diagnostic tools, researchers should be made aware that meeting the ICD-11 Gaming Disorder requires the presence of more severe symptoms in comparison to the IGD criteria in the DSM-5 (Jeong et al., 2018), meaning that fewer online gaming subjects might be identified based on the ICD-11 guidelines, impacting on prevalence rates. 
Furthermore, when measuring it, cross-culturally translated and validated instruments are needed, such as the scales by Pontes et al. (2018) and Kiraly et al. (2019).

The next region that was most represented ny studies included in this systematic literature review is North America $(n=13)$. The USA perspective on GIA is different from Asian countries, as all four studies on Internet gambling addiction, and the two studies on IP addiction were based in North America. The samples were different from the majority of the Asian samples involving mainly adolescents as the average participant age was above 20 years in ten of 13 studies. There are several reasons for this; partly because of the involvement of subjects addicted to pornography and gambling, and partly the North American sampling approach appeared to be based more on self-identification and voluntary participation than family or doctor's referral, possibly due to their older age.

No studies originating in Africa or South America were eligible for this review; this may be because these countries have low socio-economic levels which makes it difficult to develop preventative and intervention actions, because the field receives less clinical and scientific attention in those countries, or Internet penetration rates are not sufficient to make problematic Internet use a widespread problem. Technological developments in those countries should be monitored in the next decade to explore whether problematic Internet use can be considered a global phenomenon or specific to certain cultures and digital platforms.

One might suspect that the high prevalence rates of problematic Internet use in an East Asian country such as Japan (ElSalhy et al., 2019) might be caused by a high pressure to achieve well academically, and a corresponding need for a break from parental expectations. However, according to Komatsu and Rappleye (2018), competition in Japan to get into universities and the societal pressure of learning on secondary school students has decreased and is now at a similar level in comparison to their Anglo-American counterparts.

This review had some limitations. Firstly, the majority of the studies included were based on self-reports, vulnerable to psychometric problems and biases. Common limitations associated with the use of self-reports to assess GIA are often found to lose their sense of time spent due to being in a dissociative state enabled by the Internet (Greenfield, 2007), limiting trustworthy introspection for reporting time spent on the Internet. According to a study by Andrews et al. (2015) self-reported smartphone use and actual use do not match, as young people check their phones substantially more often than reported, and in a similar study de Reuver and Bouwman (2015) found self-reports to produce deceptive results. In support hereof, Jeong et al. (2018) found the false-negative rate to be relatively high (44\%) when comparing self-reports to clinical diagnoses. 
Most samples consisted of adolescents and young adults and do not represent the general population, and equally prevalence rates cannot be generalized. More representative studies are needed assessing the general population to gain insight into the dimensions of the problems associated with GIA. Samples with a wider age distribution played a part in studies such as the ones by Young (2013), involved help-seeking adults aged 22-56 years, and by King et al. (2018) involving help-seeking adult gamers aged 18-48 years, indicating problematic Internet use may be a larger problem amongst the adult population than research has revealed thus far. The included studies on online pornography addiction and problematic Internet gambling involve adult samples; further research should investigate tendencies towards online gambling and pornography use in young adults to develop prevention and treatment strategies.

Regarding recommendations for future studies, clinicians should be aware of a range of symptoms of underlying or comorbid psychopathological conditions, and pay particular attention to causality: does psychological distress predict GIA or does GIA cause an array of unhealthy mental side effects? Naturally, there may be bidirectional relationships. However, further research into the risk factors might assist in the production of valuable prevention approaches. When implementing interventions in future studies, it is advisable to recruit controls by multiple methods in order to improve representativeness (Wong et al., 2016), and according to Yao et al. (2017), problematic gamers should ideally be compared to a control group of frequent gamers rather than non-gaming healthy controls. Overall, based on the studies included here, intervening on variations on GIA appeared fruitful irrespective of treatment approach, but results from longitudinal studies are missing. The first step along this path is a longer time span between the intervention and the follow-up assessments.

The majority of the research was based on self-reports; however, the sensitivity of the tests should be improved to offer treatment to those in need of it. When developing psychometric tests, attention must be paid to avoiding compromising specificity as treatment programmes are resource-demanding and treating false positives might use funds unnecessarily and limit spaces for individuals with more severe problems who are in need of treatment. Furthermore, researchers should be aware that the content of their surveys may create or reinforce unnecessary anxiety in the subjects who respond to them (Evans et al., 2002). Mental health problems with self-harm and suicidality were not mentioned in the review on European studies on IA by (Lopez-Fernandez \& Kuss, 2019, 2020). There might be two reasons for this finding. On the one hand, these behaviours appeared not to have been assessed in European studies and on the other hand, the behaviours might be more prevalent in East Asian youth. Taking ethical 
considerations into account, self-harm behaviours and suicidality could be of considerable importance to be explored further in European and non-European contexts.

Based on the studies included in this review, future preventions should target selfregulation in school children. Future treatment programmes should focus on screening for a broad array of comorbidities. Based on the current review and the study by K. Kim and Kim (2015), involving significant others in treatment programmes is recommended, focusing on creating good family environments. Training parents in treatment aimed at children and adolescents affected by online addictions was found to be cost-effective, especially as they could potentially train other parents. CBT-based interventions are a popular approach; however equine-assisted therapy, mindfulness-based therapy, virtual reality treatment and electroacupuncture have also proven successful in reducing symptoms of online addictions. To solidify these findings, they would benefit from replication studies; future studies could advantageously explore whether outcome effect is treatment-specific. The literature included in this review generally advocates treating behavioural addictions broadly as they have common underpinnings rather than developing specific treatment procedures depending on the type of IA. The fact that the clinical scales of depression, anxiety and impulsivity had partial or full mediating effects on the ability of aggression to predict GIA could be important in regards to formulating early interventions aimed at these risk factors to prevent GIA as well as aggressive behaviour. 


\section{References}

Alexandraki, K., Stavropoulos, V., Burleigh, T. L., King, D. L., \& Griffiths, M. D. (2018). Internet pornography viewing preference as a risk factor for adolescent Internet addiction: The moderating role of classroom personality factors. Journal of Behavioral Addictions, 7(2), 423-432. https://doi.org/10.1556/2006.7.2018.34

Alimoradi, Z., Lin, C. Y., Broström, A., Bülow, P. H., Bajalan, Z., Griffiths, M. D., . . Pakpour, A. H. (2019). Internet addiction and sleep problems: A systematic review and meta-analysis. Sleep Medicine Reviews, 47, 51-61. DOI:

https://doi.org/10.1016/j.smrv.2019.06.004

Allen, J. P., Chango, J., Szwedo, D., \& Schad, M. (2014). Long-term sequelae of subclinical depressive symptoms in early adolescence. Development and Psychopathology, 26(1), 171-180. https://doi.org/10.1017/S095457941300093X

American Psychiatric Association. (2013). Diagnostic and Statistical Manual of Mental Disorders (DSM-5). Arlington, VA: American Psychiatric Association.

Andrews, S., Ellis, D. A., Shaw, H., \& Piwek, L. (2015). Beyond self-report: Tools to compare estimated and real-world smartphone use. PLoS One; San Francisco, 10(10), e0139004. http://dx.doi.org.ep.fjernadgang.kb.dk/10.1371/journal.pone.0139004

Apisitwasana, N., Perngparn, U., \& B Cottler, L. (2018). Effectiveness of school- and familybased interventions to prevent gaming addiction among grades 4-5 students in Bangkok, Thailand. Psychology Research and Behavior Management, 11, 103-115. https://doi.org/10.2147/PRBM.S145868

Bipeta, R., Yerramilli, S. S., Karredla, A. R., \& Gopinath, S. (2015). Diagnostic stability of Internet addiction in Obsessive-compulsive Disorder: Data from a naturalistic one-year treatment study. Innovations in Clinical Neuroscience, 12(3-4), 14-23.

Chamberlain, S. R., Redden, S. A., Leppink, E., \& Grant, J. E. (2017). Problematic internet use in gamblers: Impact on clinical and cognitive measures. CNS Spectrums, 22(6), 495503. https://doi.org/10.1017/S1092852917000037

Chen, L., \& Nath, R. (2016). Understanding the underlying factors of Internet addiction across cultures: A comparison study. Electronic Commerce Research and Applications, 17, 38-48. https://doi.org/10.1016/j.elerap.2016.02.003

Chen, S.-H., Weng, L.-J., Su, Y.-J., Wu, H.-M., \& Yang, P.-F. (2003). Development of a Chinese Internet Addiction Scale and its psychometric study. Chinese Journal of Psychology, 45(3), 279-294.

Choi, J., Cho, H., Lee, S., Kim, J., \& Park, E. C. (2018). Effect of the online game shutdown 
policy on internet use, internet addiction, and sleeping hours in Korean

adolescents. Journal of Adolescent Health, 62(5), 548-555.

https://doi.org/10.1016/j.jadohealth.2017.11.291

Cole, S. H., \& Hooley, J. M. (2013). Clinical and personality correlates of MMO gaming: Anxiety and absorption in Problematic Internet Use. Social Science Computer Review, 31(4), 424-436. https://doi.org/10.1177/0894439312475280

Crosby, J. M., \& Twohig, M. P. (2016). Acceptance and Commitment Therapy for problematic Internet pornography use: A randomized trial. Behavior Therapy, 47(3), 355-366. https://doi.org/10.1016/j.beth.2016.02.001

Davis R. A. (2001). A cognitive-behavioral model of pathological Internet use. Computers in Human Behavior 17, 187-195. https://doiorg.ezproxy.lib.monash.edu.au/10.1016/S0747-5632(00)00041-8

Dayal, R., Kalokhe, A. S., Choudhry, V., Pillai, D., Beier, K., \& Patel, V. (2018). Ethical and definitional considerations in research on child sexual violence in India. BMC Public Health, 18(1), 1144. https://doi.org/10.1186/s12889-018-6036-y

de Reuver, M., \& Bouwman, H. (2015). Dealing with self-report bias in mobile Internet acceptance and usage studies. Information \& Management, 52(3), 287-294. https://doi.org/10.1016/j.im.2014.12.002

Dufour, M., Gagnon, S. R., Nadeau, L., Légaré, A.-A., \& Laverdière, É. (2019). Clinical profile of adolescents being treated for problematic internet use. The Canadian Journal of Psychiatry, 64(2), 136-144. https://doi.org/10.1177/0706743718800698

ElSalhy, M., Miyazaki, T., Noda, Y., Nakajima, S., Nakayama, H., Mihara, S., ... Mimura, M. (2019). Relationships between Internet addiction and clinicodemographic and behavioral factors. Neuropsychiatric Disease and Treatment; Auckland, 15, 739-752. http://dx.doi.org.ep.fjernadgang.kb.dk/10.2147/NDT.S193357

Erden, S., \& Hatun, O. (2015). The use of cognitive-behavioral therapy in coping with Internet addiction: A case study. Addicta - The Turkish Journal on Addictions, 2(1), 7083. https://doi.org/10.15805/addicta.2015.2.1.015

Evans, M., Robling, M., Rapport, F. M., Houston, H., Kinnersley, P., \& Wilkinson, C. (2002). It doesn't cost anything just to ask, does it? The ethics of questionnaire-based research. Journal of Medical Ethics, 28(1), 41-44. https://doi.org/10.1136/jme.28.1.41

Festl, R., Scharkow, M., \& Quandt, T. (2013). Problematic computer game use among adolescents, younger and older adults: Problematic computer game use. Addiction, 108(3), 592-599. https://doi.org/10.1111/add.12016 
Gainsbury, S. M., Russell, A., Blaszczynski, A., \& Hing, N. (2015). Greater involvement and diversity of Internet gambling as a risk factor for problem gambling. European Journal of Public Health, 25(4), 723-728. https://doi.org/10.1093/eurpub/ckv006

Gansner, M., Belfort, E., Cook, B., Leahy, C., Colon-Perez, A., Mirda, D., \& Carson, N. (2019). Problematic Internet Use and associated high-risk behavior in an adolescent clinical sample: Results from a survey of psychiatrically hospitalized youth.

Cyberpsychology, Behavior, and Social Networking, 22(5), 349-354. https://doi.org/10.1089/cyber.2018.0329

Gao, T., Hu, Y., Qin, Z., Cao, R., Liu, S., Mei, S., \& Meng, X. (2019). The role of school connectedness and maladaptive cognitions in the association between stress and Internet addiction: A serial mediation model. Perspectives in Psychiatric Care, 55, 728-733. https://doi.org/10.1111/ppc.12417

Goldstein, R. Z., \& Volkow, N. D. (2002). Drug addiction and its underlying neurobiological basis: Neuroimaging evidence for the involvement of the frontal cortex. The American Journal of Psychiatry, 159(10), 1642-1652. https://doi.org/10.1176/appi.ajp.159.10.1642

Greenfield, D. (2007). The addictive properties of Internet usage. In K. S. Young \& C. N. de Abreu (Eds.), Internet Addiction (pp. 133-153).

https://doi.org/10.1002/9781118013991.ch8

Griffiths, M. (2005). A 'components' model of addiction within a biopsychosocial framework. Journal of Substance Use, 10(4), 191-197. https://doi.org/10.1080/14659890500114359

Griffiths, M. D., van Rooij, A. J., Kardefelt-Winther, D., Starcevic, V., Kiraly, O., Pallesen, S., ... Demetrovics, Z. (2016). Working towards an international consensus on criteria for assessing internet gaming disorder: A critical commentary on Petry et al. (2014). Addiction, 111(1), 167-175. https://doi.org/10.1111/add.13057

Han, D. H., Yoo, M., Renshaw, P. F., \& Petry, N. M. (2018). A cohort study of patients seeking Internet gaming disorder treatment. Journal of Behavioral Addictions, 7(4), 930938. https://doi.org/10.1556/2006.7.2018.102

Han, X., Wang, Y., Jiang, W., Bao, X., Sun, Y., Ding, W., ... Zhou, Y. (2018). Resting-state activity of prefrontal-striatal circuits in Internet Gaming Disorder: Changes with cognitive behavior therapy and predictors of treatment response. Frontiers in Psychiatry, 9, 341. https://doi.org/10.3389/fpsyt.2018.00341

Harris, N., \& Mazmanian, D. (2016a). Cognitive behavioural group therapy for problem gamblers who gamble over the Internet: A controlled study. Journal of Gambling Issues, 
33, 170-188. https://doi.org/10.4309/jgi.2016.33.10

Harris, N., \& Mazmanian, D. (2016b). Problem Internet gamblers' perspectives on cognitive behavioural group therapy. International Journal of Mental Health and Addiction, 14(6), 885-895. https://doi.org/10.1007/s11469-015-9622-6

Hasan, A. A.-H., \& Jaber, A. A. (2019). Prevalence of internet addiction, its association with psychological distress, coping strategies among undergraduate students. Nurse Education Today, 81, 78-82. https://doi.org/10.1016/j.nedt.2019.07.004

Hou, J., Jiang, Y., Chen, S., Hou, Y., Wu, J., Fan, N., \& Fang, X. (2019). Cognitive mechanism of intimate interpersonal relationships and loneliness in internet-addicts: An ERP study. Addictive Behaviors Reports, 10. https://doi.org/10.1016/j.abrep.2019.100209 Jeong, H., Yim, H. W., Lee, S.-Y., Lee, H. K., Potenza, M. N., Kwon, J.-H., ... Choi, J.-S. (2018). Discordance between self-report and clinical diagnosis of Internet gaming disorder in adolescents. Scientific Reports, 8, 10084. https://doi.org/10.1038/s41598-018$28478-8$

Jo, Y. S., Bhang, S. Y., Choi, J. S., Lee, H. K., Lee, S. Y., \& Kweon, Y.-S. (2019). Clinical characteristics of diagnosis for Internet Gaming Disorder: Comparison of DSM-5 IGD and ICD-11 GD Diagnosis. Journal of Clinical Medicine, 8(7), 945. https://doi.org/10.3390/jcm8070945

Kalivas, P. W., \& Volkow, N. D. (2005). The neural basis of addiction: A pathology of motivation and choice. The American Journal of Psychiatry, 162(8), 1403-1413. https://doi.org/10.1176/appi.ajp.162.8.1403

Kang, K. D., Han, D. H., Jung, T. W., \& Park, I. H. (2018). Effects of equine-assisted activities and therapies on the affective network of adolescents with Internet Gaming Disorder. Journal of Alternative \& Complementary Medicine, 24(8), 841-849. https://doi.org/10.1089/acm.2017.0416

Kawabe, K., Horiuchi, F., Oka, Y., \& Ueno, S. (2019). Association between sleep habits and problems and Internet addiction in adolescents. Psychiatry Investigation, 16(8), 581-587. https://doi.org/10.30773/pi.2019.03.21.2

Kessler, R. C., Andrews, G., Colpe, L. J., Hiripi, E., Mroczek, D. K., Normand, S.-L. T., ... Zaslavsky, A. M. (2002). Short screening scales to monitor population prevalences and trends in non-specific psychological distress. Psychological Medicine, 32(6), 959-976. https://doi.org/10.1017/S0033291702006074

Khazaei, F., Khazaei, O., \& Ghanbari-H., B. (2017). Positive psychology interventions for internet addiction treatment. Computers in Human Behavior, 72, 304-311. 
https://doi.org/10.1016/j.chb.2017.02.065

Kim, J. Y., Lee, J. S., \& Oh, S. (2017). A path model of school violence perpetration: Introducing online game addiction as a new risk factor. Journal of Interpersonal Violence, 32(21), 3205-3225. https://doi.org/10.1177/0886260515597435

Kim, K., \& Kim, K. (2015). Internet game addiction, parental attachment, and parenting of adolescents in South Korea. Journal of Child \& Adolescent Substance Abuse, 24(6), 366371. https://doi.org/10.1080/1067828X.2013.872063

Kim, P. W., Kim, S. Y., Shim, M., Im, C.-H., \& Shon, Y.-M. (2013). The influence of an educational course on language expression and treatment of gaming addiction for massive multiplayer online role-playing game (MMORPG) players. Computers \& Education, 63, 208-217. https://doi.org/10.1016/j.compedu.2012.12.008

Kim, S.-H., Yim, H.-W., Jo, S.-J., Jung, K.-I., Lee, K., \& Park, M.-H. (2018). The effects of group cognitive behavioral therapy on the improvement of depression and anxiety in adolescents with Problematic Internet Use. Journal of the Korean Academy of Child and Adolescent Psychiatry, 29(2), 73-78. https://doi.org/10.5765/jkacap.2018.29.2.73

King, D. L., Adair, C., Saunders, J. B., \& Delfabbro, P. H. (2018). Clinical predictors of gaming abstinence in help-seeking adult problematic gamers. Psychiatry Research, 261, 581-588. https://doi.org/10.1016/j.psychres.2018.01.008

King, D. L., Delfabbro, P. H., Doh, Y. Y., Wu, A. M. S., Kuss, D. J., Pallesen, S., ... Sakuma, H. (2018). Policy and prevention approaches for disordered and hazardous gaming and Internet use: An international perspective. Prevention Science; New York, 19(2), 233-249. http://dx.doi.org.ep.fjernadgang.kb.dk/10.1007/s11121-017-0813-1

King, D. L., Delfabbro, P., Wu, A., Doh, Y. Y., Kuss, D. J., Pallesen, S., . . Sakuma, H. (2017). Treatment of Internet gaming disorder: An international systematic review and CONSORT evaluation. Clinical Psychology Review, 54, 123-133. https://doi.org/10.1016/j.cpr.2017.04.002

King, D. L., Delfabbro, P. H., \& Griffiths, M. D. (2012). Clinical interventions for technology-based problems: Excessive Internet and video game use. Journal of Cognitive Psychotherapy, 26(1), 43-56. https://doi.org/10.1891/0889-8391.26.1.43

Király, O., Bőthe, B., Ramos-Diaz, J., Rahimi-Movaghar, A., Lukavska, K., Hrabec, O., ... \& Karila, L. (2019). Ten-item Internet Gaming Disorder Test (IGDT-10): Measurement invariance and cross-cultural validation across seven language-based samples. Psychology of Addictive Behaviors, 33(1), 91. https://doi.org/10.1037/adb0000433 
Koh, Y. S. (2017). The Korean national policy for Internet addiction. In Internet addiction (pp. 323-336). Springer, Cham.

Komatsu, H., \& Rappleye, J. (2018). Is exam hell the cause of high academic achievement in East Asia? The case of Japan and the case for transcending stereotypes. British Educational Research Journal, 44(5), 802-826. https://doi.org/10.1002/berj.3468

Koo, H. J., Han, D. H., Park, S.-Y., \& Kwon, J.-H. (2017). The Structured Clinical Interview for DSM-5 Internet Gaming Disorder: Development and validation for diagnosing IGD in adolescents. Psychiatry Investigation, 14(1), 21-29. https://doi.org/10.4306/pi.2017.14.1.21

Korean National Information Society Agency. (2013). A Validation Study of K-Scale as a Diagnostic Tool. Seoul, Korea: Korean National Information Society Agency Report.

Krossbakken, E., Torsheim, T., Mentzoni, R. A., King, D. L., Bjorvatn, B., Lorvik, I. M., \& Pallesen, S. (2018). The effectiveness of a parental guide for prevention of problematic video gaming in children: A public health randomized controlled intervention study. Journal of Behavioral Addictions, 7(1), 52-61. https://doi.org/10.1556/2006.6.2017.087

Kuss, D. J. (2013). Internet gaming addiction: Current perspectives. Psychology Research and Behavior Management, 6, 125-137. https://doi.org/10.2147/PRBM.S39476

Kuss, D. J., Griffiths, M. D., \& Binder, J. F. (2013). Internet addiction in students: Prevalence and risk factors. Computers in Human Behavior, 29, 959-966. https://doi.org/10.1016/j.chb.2012.12.024

Kuss, D. J., \& Griffiths, M. D. (2012). Online gaming addiction in children and adolescents: A review of empirical research. Journal of Behavioral Addictions, 1(1), 3-22. https://doi.org/10.1556/JBA.1.2012.1.1

Kuss, D. J., \& Lopez-Fernandez, O. (2016). Internet addiction and problematic Internet use: A systematic review of clinical research. World Journal of Psychiatry, 6(1), 143-176. https://doi.org/10.5498/wjp.v6.i1.143

Kuss, D. J. (2017). Mobile technology and social media: The "extensions of man" in the 21 st Century. Human Development, 60, 141-143. https://doi.org/10.1159/000479842

Laconi, Stéphanie, Kaliszewska-Czeremska, K., Gnisci, A., Sergi, I., Barke, A., Jeromin, F., ... Kuss, D. J. (2018). Cross-cultural study of Problematic Internet Use in nine European countries. Computers in Human Behavior, 84, 430-440. https://doi.org/10.1016/j.chb.2018.03.020

Laconi, Stephanie, Rodgers, R. F., \& Chabrol, H. (2014). The measurement of Internet addiction: A critical review of existing scales and their psychometric properties. 
Computers in Human Behavior, 41, 190-202. https://doi.org/10.1016/j.chb.2014.09.026

Lai, C.-M., Mak, K.-K., Watanabe, H., Ang, R. P., Pang, J. S., \& Ho, R. C. M. (2013).

Psychometric properties of the Internet Addiction Test in Chinese adolescents. Journal of Pediatric Psychology, 38(7), 794-807. https://doi.org/10.1093/jpepsy/jst022

Lai, C. M., Mak, K. K., Cheng, C., Watanabe, H., Nomachi, S., Bahar, N., ... \& Griffiths, M. D. (2015). Measurement invariance of the internet addiction test among Hong Kong, Japanese, and Malaysian adolescents. Cyberpsychology, Behavior, and Social Networking, 18(10), 609-617. https://doi.org/10.1089/cyber.2015.0069

Lee, S. Y., \& Kwon, J. H. (2001). Impulsivity, social problem-solving abilities, and communication style of adolescent internet game addiction. The Korean Journal of Clinical Psychology, 20, 67-80.

Lee, S.-Y., Lee, H. K., Bang, S., Jeong, H., Yim, H. W., \& Kweon, Y.-S. (2018). Aggression and harm-avoidant trait impede recovery from Internet Gaming Disorder. Frontiers in Psychiatry, 9. https://doi.org/10.3389/fpsyt.2018.00263

Leong, F. T. L., Okazaki, S., \& Tak, J. (2003). Assessment of depression and anxiety in East Asia. Psychological Assessment, 15(3), 290-305. https://doi.org/10.1037/10403590.15.3.290

Li, A. Y., Chau, C., \& Cheng, C. (2019). Development and validation of a parent-based program for preventing Gaming Disorder: The game over intervention. International Journal of Environmental Research and Public Health, 16(11), 1984. https://doi.org/10.3390/ijerph16111984

Li, W., Garland, E. L., \& Howard, M. O. (2018). Therapeutic mechanisms of MindfulnessOriented Recovery Enhancement for internet gaming disorder: Reducing craving and addictive behavior by targeting cognitive processes. Journal of Addictive Diseases, 37(12), 5-13. https://doi.org/10.1080/10550887.2018.1442617

Liang, L., Zhou, D., Yuan, C., Shao, A., \& Bian, Y. (2016). Gender differences in the relationship between internet addiction and depression: A cross-lagged study in Chinese adolescents. Computers in Human Behavior, 63, 463-470. https://doi.org/10.1016/j.chb.2016.04.043

Lim, J.-A., Gwak, A. R., Park, S. M., Kwon, J.-G., Lee, J.-Y., Jung, H. Y., ... Choi, J.-S. (2015). Are adolescents with Internet addiction prone to aggressive behavior? The mediating effect of clinical comorbidities on the predictability of aggression in adolescents with Internet addiction. CyberPsychology, Behavior \& Social Networking, 18(5), 260-267. https://doi.org/10.1089/cyber.2014.0568 
Lin, C.-H., Wang, C.-C., Sun, J.-H., Ko, C.-H., \& Chiu, Y.-C. (2019). Is the clinical version of the Iowa Gambling Task relevant for assessing choice behavior in cases of Internet addiction? Frontiers in Psychiatry, 10, 232. https://doi.org/10.3389/fpsyt.2019.00232

Lin, P.-H., Lee, Y.-C., Chen, K.-L., Hsieh, P.-L., Yang, S.-Y., \& Lin, Y.-L. (2019). The relationship between sleep quality and Internet addiction among female college students. Frontiers in Neuroscience, 13. https://doi.org/10.3389/fnins.2019.00599

Lin, I. H., Ko, C. H., Chang, Y. P., Liu, T. L., Wang, P. W., Lin, H. C., .. Yen, C. F. (2014). The association between suicidality and Internet addiction and activities in Taiwanese adolescents. Comprehensive Psychiatry, 55(3), 504-510. https://doi.org/10.1016/j.comppsych.2013.11.012

Liu, H.-C., Liu, S.-I., Tjung, J.-J., Sun, F.-J., Huang, H.-C., \& Fang, C.-K. (2017). Self-harm and its association with internet addiction and internet exposure to suicidal thought in adolescents. Journal of the Formosan Medical Association, 116(3), 153-160. https://doi.org/10.1016/j.jfma.2016.03.010

Liu, Q.-X., Fang, X.-Y., Yan, N., Zhou, Z.-K., Yuan, X.-J., Lan, J., \& Liu, C.-Y. (2015). Multi-family group therapy for adolescent Internet addiction: Exploring the underlying mechanisms. Addictive Behaviors, 42, 1-8. https://doi.org/10.1016/j.addbeh.2014.10.021 Lopez-Fernandez, O. (2018). Generalised versus specific Internet use-related addiction problems: A mixed methods study on Internet, gaming, and social networking behaviours. International Journal of Environmental Research and Public Health, 15(12), 2913. DOI: 10.3390/ijerph15122913

Lopez-Fernandez, O. (2015). Cross-cultural research in internet addiction: A systematic review. International Archives of Addiction Research and Medicine, 1(2), 011.

Lopez-Fernandez, O., Honrubia-Serrano, L., Freixa-Blanxart, M., \& Gibson, W. (2014). Prevalence of problematic mobile phone use in British adolescents. Cyberpsychology, Behavior, and Social Networking, 17(2),91-98.http://doi.org/10.1089/cyber.2012.0260 Lopez-Fernandez, O., Griffiths, M. D., Kuss, D. J., Dawes, C., Pontes, H. M., Justice, L., ... \& Männikkö, N. (2019). Cross-cultural validation of the Compulsive Internet Use Scale in four forms and eight languages. Cyberpsychology, Behavior, and Social Networking, 22(7), 451-464. https://doi.org/10.1089/cyber.2018.0731 Lopez-Fernandez, O., \& Kuss, D. J. (2019). Harmful internet use. Study Part I. (European Parliamentary Research Service, Ed.). Available online: https://www.europarl.europa.eu/stoa/en/document/EPRS_STU(2019)624249 (accessed on 29 February 2020). 
Lopez-Fernandez, O., \& Kuss, D. J. (2020). Preventing Harmful Internet Use-Related Addiction Problems in Europe: A Literature Review and Policy Options. International Journal of Environmental Research and Public Health, 17(11), 3797. doi:10.3390/ijerph17113797 .

Mallorquí-Bagué, N., Fernández-Aranda, F., Lozano-Madrid, M., Granero, R., Mestre-Bach, G., Baño, M., ... Jiménez-Murcia, S. (2017). Internet gaming disorder and online gambling disorder: Clinical and personality correlates. Journal of Behavioral Addictions, 6(4), 669-677. https://doi.org/10.1556/2006.6.2017.078

Mamun, M. A., Hossain, Md. S., Siddique, A. B., Sikder, Md. T., Kuss, D. J., \& Griffiths, M. D. (2019). Problematic internet use in Bangladeshi students: The role of sociodemographic factors, depression, anxiety, and stress. Asian Journal of Psychiatry, 44, 48-54. https://doi.org/10.1016/j.ajp.2019.07.005

Manwong, M., Lohsoonthorn, V., Booranasuksakul, T., \& Chaikoolvatana, A. (2018). Effects of a group activity-based motivational enhancement therapy program on social media addictive behaviors among junior high school students in Thailand: A cluster randomized trial. Psychology Research and Behavior Management, 11, 329-339. https://doi.org/10.2147/PRBM.S168869

Matuszczak-Świgoń, J., \& Bednarowska, W. (2019). Cognitive behavioural therapy of Internet addiction. Psychoterapia, 188(1), 63-73. https://doi.org/10.12740/PT/109067

McLeod, G. F. H., Horwood, L. J., \& Fergusson, D. M. (2016). Adolescent depression, adult mental health and psychosocial outcomes at 30 and 35 years. Psychological Medicine, 46(7), 1401-1412. https://doi.org/10.1017/S0033291715002950

Medic, G., Wille, M., \& Hemels, M. E. (2017). Short- and long-term health consequences of sleep disruption. Nature and Science of Sleep, 9, 151-161. https://doi.org/10.2147/NSS.S134864

Montag, C., Bey, K., Sha, P., Li, M., Chen, Y. F., Liu, W. Y., ... \& Reuter, M. (2015). Is it meaningful to distinguish between generalized and specific Internet addiction? Evidence from a cross-cultural study from Germany, Sweden, Taiwan and China. Asia-Pacific Psychiatry, 7(1), 20-26. https://doi-org.ezproxy.lib.monash.edu.au/10.1111/appy.12122

Meerkerk, G. J., Van Den Eijnden, R. J., Vermulst, A. A., \& Garretsen, H. F. (2009). The Compulsive Internet Use Scale (CIUS): Some psychometric properties. Cyberpsychology \& Behavior, 12(1), 1-6. https://doi.org/10.1089/cpb.2008.0181

Na, E., Lee, H., Choi, I., \& Kim, D.-J. (2017). Comorbidity of Internet gaming disorder and alcohol use disorder: A focus on clinical characteristics and gaming patterns. American 
Journal on Addictions, 26(4), 326-334. https://doi.org/10.1111/ajad.12528

O’Brien, J. E., Li, W., Snyder, S. M., \& Howard, M. O. (2016). Problem Internet overuse behaviors in college students: Readiness-to-change and receptivity to treatment. Journal of Evidence-Informed Social Work, 13(4), 373-385. https://doi.org/10.1080/23761407.2015.1086713

Owens, J., Adolescent Sleep Working Group, \& Committee on Adolescence. (2014). Insufficient sleep in adolescents and young adults: An update on causes and consequences. Pediatrics, 134(3), e921-932. https://doi.org/10.1542/peds.2014-1696

Pan, P.-Y., \& Yeh, C.-B. (2018). Internet addiction among adolescents may predict selfharm/suicidal behavior: A prospective study. Journal of Pediatrics, 197, 262-267. https://doi.org/10.1016/j.jpeds.2018.01.046

Park, S., Jeon, H. J., Bae, J. N., Seong, S. J., \& Hong, J. P. (2017). Prevalence and psychiatric comorbidities of Internet addiction in a nationwide sample of Korean adults. Psychiatry investigation, 14(6), 879-882. https://doi.org/10.4306/pi.2017.14.6.879

Park, S. Y., Kim, S. M., Roh, S., Soh, M.-A., Lee, S. H., Kim, H., ... Han, D. H. (2016). The effects of a virtual reality treatment program for online gaming addiction. Computer Methods and Programs in Biomedicine, 129, 99-108. https://doi.org/10.1016/j.cmpb.2016.01.015

Park, T. Y., Kim, S., \& Lee, J. (2014). Family therapy for an Internet-addicted young adult with interpersonal problems. Journal of Family Therapy, 36(4), 394-419. https://doi.org/10.1111/1467-6427.12060

Parker, J. D. A., Summerfeldt, L. J., Taylor, R. N., Kloosterman, P. H., \& Keefer, K. V. (2013). Problem gambling, gaming and Internet use in adolescents: Relationships with emotional intelligence in clinical and special needs samples. Personality and Individual Differences, 55(3), 288-293. https://doi.org/10.1016/j.paid.2013.02.025

Pontes, H. M., Stavropoulos, V., \& Griffiths, M. D. (2017). Measurement invariance of the internet gaming disorder scale-short-form (IGDS9-SF) between the United States of America, India and the United Kingdom. Psychiatry Research, 257, 472-478. https://doi.org/10.1016/j.psychres.2017.08.013

Rial, A., Golpe, S., Isorna, M., Braña, T., \& Gómez, P. (2018). Minors and problematic Internet use: Evidence for better prevention. Computers in Human Behavior, 87, 140145. https://doi.org/10.1016/j.chb.2018.05.030

Robbins, T., \& Clark, L. (2015). Behavioral addictions. Current Opinion in Neurobiology, 30, 66-72. https://doi.org/10.1016/j.conb.2014.09.005 
Rumpf, H. J., Vermulst, A. A., Bischof, A., Kastirke, N., Guertler, D., Bischof, G., ... Meyer, C. (2014). Occurrence of Internet addiction in a general population sample: A latent class analysis. European Addiction Research, 20(4), 159-166. DOI: 10.1159/000354321

Ryu, H., Lee, J. Y., Choi, A. R., Chung, S. J., Park, M., Bhang, S.-Y., .. Choi, J.-S. (2019). Application of Diagnostic Interview for Internet Addiction (DIA) in clinical practice for Korean adolescents. Journal of Clinical Medicine, 8(2), 202. https://doi.org/10.3390/jcm8020202

Sakuma, H., Mihara, S., Nakayama, H., Miura, K., Kitayuguchi, T., Maezono, M., ... Higuchi, S. (2017). Treatment with the Self-Discovery Camp (SDiC) improves Internet gaming disorder. Addictive Behaviors, 64, 357-362. https://doi.org/10.1016/j.addbeh.2016.06.013

Seki, T., Hamazaki, K., Natori, T., \& Inadera, H. (2019). Relationship between internet addiction and depression among Japanese university students. Journal of Affective Disorders, 256, 668-672. https://doi.org/10.1016/j.jad.2019.06.055

Senormanci, O., Konkan, R., Guclu, O., \& Senormanci, G. (2014). Depression, loneliness, anger behaviours and interpersonal relationship styles in male patients admitted to Internet addiction outpatient clinic. Psychiatria Danubina, 26(1), 39-45.

Seong, W., Hong, J. S., Kim, S., Kim, S. M., \& Han, D. H. (2019). Personality and psychological factors of problematic Internet gamers seeking hospital treatment. Frontiers in Psychiatry, 10, 583. https://doi.org/10.3389/fpsyt.2019.00583

Shahrbabaki, B. N., Fallahi, A., \& Pirakalathanan, P. (2017). Expressed needs of students for prevention of Internet addiction: A content analysis study. Health Scope, 6(3), e15104. https://doi.org/10.5812/jhealthscope.15104

Shamseer, L., Moher, D., Clarke, M., Ghersi, D., Liberati, A., Petticrew, M., Shekelle, P., \& Stewart, L. A. (2015). Preferred reporting items for systematic review and meta-analysis protocols (PRISMA-P) 2015: Elaboration and explanation. BMJ, 349, g7647. https://doi.org/10.1136/bmj.g7647

Shek, D. T. L., Tang, V. M. Y., \& Lo, C. Y. (2008). Internet addiction in Chinese adolescents in Hong Kong: Assessment, profiles, and psychosocial correlates. The Scientific World Journal, 8, 776-787. https://doi.org/10.1100/tsw.2008.104

Short, M. B., Wetterneck, C. T., Bistricky, S. L., Shutter, T., \& Chase, T. E. (2016). Clinicians' beliefs, observations, and treatment effectiveness regarding clients' sexual addiction and Internet pornography use. Community Mental Health Journal, 52(8), 10701081. https://doi.org/10.1007/s10597-016-0034-2 
So, R., Makino, K., Fujiwara, M., Hirota, T., Ohcho, K., Ikeda, S., ... Inagaki, M. (2017). The prevalence of Internet addiction among a Japanese adolescent psychiatric clinic sample with Autism Spectrum Disorder and/or Attention-Deficit Hyperactivity Disorder: A Cross-Sectional Study. Journal of Autism and Developmental Disorders, 47(7), 22172224. https://doi.org/10.1007/s10803-017-3148-7

So, R., Makino, K., Hirota, T., Fujiwara, M., Ocho, K., Ikeda, S., .. Inagakip, M. (2019). The 2-year course of Internet addiction among a Japanese adolescent psychiatric clinic sample with Autism Spectrum Disorder and/or Attention-Deficit Hyperactivity Disorder. Journal of Autism and Developmental Disorders. https://doi.org/10.1007/s10803-01904169-9

Starcevic, V. (2013). Is Internet addiction a useful concept? Australian \& New Zealand Journal of Psychiatry, 47(1), 16-19. https://doi.org/10.1177/0004867412461693

Starcevic, V., \& Aboujaoude, E. (2016). Internet addiction: Reappraisal of an increasingly inadequate concept. CNS Spectrums, 22(1), 7-13. DOI: 10.1017/S1092852915000863

Sul, S. (2015). Determinants of internet game addiction and therapeutic role of family leisure participation. Journal of Inclusion Phenomena and Macrocyclic Chemistry, 82(1-2), 271-278. https://doi.org/10.1007/s10847-015-0508-9

Tang, C. S. K., Wu, A. M. S., Yan, E. C. W., Ko, J. H. C., Kwon, J. H., Yogo, M., ... Koh, Y. Y. W. (2018). Relative risks of Internet-related addictions and mood disturbances among college students: A 7-country/region comparison. Public Health, 165, 16-25. https://doi.org/10.1016/j.puhe.2018.09.010

Tang, J., Zhang, Y., Li, Y., Liu, L., Liu, X., Zeng, H., ... Lee, T. S.-H. (2014). Clinical characteristics and diagnostic confirmation of Internet addiction in secondary school students in Wuhan, China. Psychiatry and Clinical Neurosciences, 68(6), 471-478. https://doi.org/10.1111/pcn.12153

Tateno, M., Teo, A. R., Ukai, W., Kanazawa, J., Katsuki, R., Kubo, H., \& Kato, T. A. (2019). Internet addiction, smartphone addiction, and hikikomori trait in Japanese young adult: Social isolation and social network. Frontiers in Psychiatry, 10. https://doi.org/10.3389/fpsyt.2019.00455

Torres-Rodríguez, A., Griffiths, M. D., \& Carbonell, X. (2018). The treatment of Internet gaming disorder: A brief overview of the PIPATIC program. International Journal of Mental Health and Addiction, 16(4), 1000-1015. https://doi.org/10.1007/s11469-0179825-0

Torres-Rodríguez, A., Griffiths, M. D., Carbonell, X., Farriols-Hernando, N., \& Torres- 
Jimenez, E. (2017). Internet gaming disorder treatment: A case study evaluation of four different types of adolescent problematic gamers. International Journal of Mental Health and Addiction. https://doi.org/10.1007/s11469-017-9845-9

Turel, O., Mouttapa, M., \& Donato, E. (2015). Preventing problematic Internet use through video-based interventions: A theoretical model and empirical test. Behaviour \& Information Technology, 34(4), 349-362. https://doi.org/10.1080/0144929X.2014.936041

van Rooij, A. J., Schoenmakers, T. M., Vermulst, A. A., van den Eijnden, R. J. J. M., \& van de Mheen, D. (2011). Online video game addiction: Identification of addicted adolescent gamers. Addiction, 106(1), 205-212. https://doi.org/10.1111/j.1360-0443.2010.03104.x

Wang, G. Y., \& Griskova-Bulanova, I. (2018). Electrophysiological activity is associated with vulnerability of Internet addiction in non-clinical population. Addictive Behaviors, 84, 33-39. https://doi.org/10.1016/j.addbeh.2018.03.025

Widyanto, L., \& McMurran, M. (2004). The Psychometric Properties of the Internet Addiction Test. CyberPsychology \& Behavior, 7(4), 443-450. https://doi.org/10.1089/cpb.2004.7.443

Williams, R. J., Lee, C.-K., \& Back, K. J. (2013). The prevalence and nature of gambling and problem gambling in South Korea. Social Psychiatry and Psychiatric Epidemiology, 48(5), 821-834. https://doi.org/10.1007/s00127-012-0580-z

Wölfling, K., Beutel, M. E., Dreier, M., \& Müller, K. W. (2015). Bipolar spectrum disorders in a clinical sample of patients with Internet addiction: Hidden comorbidity or differential diagnosis? Journal of Behavioral Addictions, 4(2), 101-105. DOI: 10.1556/2006.4.2015.011.

Wong, C. K., Horn-Ross, P. L., Gee, G. C., Shariff-Marco, S., Quach, T., Allen, L., ... Gomez, S. L. (2016). Strategies for recruiting representative samples of Asian Americans for a population-based case-control study. Journal of Epidemiology and Community Health, 70(10), 974-982. https://doi.org/10.1136/jech-2015-206905

World Health Organization. (2019). International Classification of Diseases (ICD-11). Geneva, Switzerland: World Health Organization.

Yang, Sun-Yi, \& Kim, H.-S. (2018). Effects of a prevention program for internet addiction among middle school students in South Korea. Public Health Nursing, 35(3), 246-255. https://doi.org/10.1111/phn.12394

Yang, Shang-Yu, Fu, S.-H., Chen, K.-L., Hsieh, P.-L., \& Lin, P.-H. (2019). Relationships between depression, health-related behaviors, and internet addiction in female junior 
college students. PLoS ONE, 14(8). https://doi.org/10.1371/journal.pone.0220784

Yang, Y., Li, H., Chen, X., Zhang, L., Huang, B., \& Zhu, T. (2017). Electro-acupuncture treatment for internet addiction: Evidence of normalization of impulse control disorder in adolescents. Chinese Journal of Integrative Medicine, 23(11), 837-844. https://doi.org/10.1007/s11655-017-2765-5

Yao, Y.-W., Chen, P.-R., Li, C. R., Hare, T. A., Li, S., Zhang, J.-T., ... Fang, X.-Y. (2017). Combined reality therapy and mindfulness meditation decrease intertemporal decisional impulsivity in young adults with Internet gaming disorder. Computers in Human Behavior, 68, 210-216. https://doi.org/10.1016/j.chb.2016.11.038

Yeh, Y.-C., Wang, P.-W., Huang, M.-F., Lin, P.-C., Chen, C.-S., \& Ko, C.-H. (2017a). The procrastination of Internet gaming disorder in young adults: The clinical severity. Psychiatry Research, 254, 258-262. https://doi.org/10.1016/j.psychres.2017.04.055

Young, K. S. (1998a). Caught in the net: How to recognize the signs of Internet addiction-and a winning strategy for recovery. New York: Wiley.

Young, K. S. (1998b). Internet Addiction: The emergence of a new clinical disorder. CyberPsychology \& Behavior, 1(3), 237-244. https://doi.org/10.1089/cpb.1998.1.237

Young, K. S. (2013). Treatment outcomes using CBT-IA with Internet-addicted patients. Journal of Behavioral Addictions, 2(4), 209. https://doi.org/10.1556/JBA.2.2013.4.3

Youth Risk Behavior Survey. (2018). Retrieved 10 November 2018, from Centers of Disease Control and Prevention website: www.cdc.gov/yrbs

Yu, J.-H., \& Park, T.-Y. (2016). Family therapy for an adult child experiencing bullying and game addiction: An application of Bowenian and MRI theories. Contemporary Family Therapy, 38(3), 318-327. https://doi.org/10.1007/s10591-016-9382-x 